\title{
Estimations of global shortwave direct aerosol radiative effects above opaque water clouds using a combination of A-Train satellite sensors
}

\author{
Meloë S. Kacenelenbogen ${ }^{1}$, Mark A. Vaughan ${ }^{3}$, Jens Redemann ${ }^{4}$, Stuart A. Young ${ }^{5}$, Zhaoyan Liu ${ }^{3,5}$, Yongxiang Hu ${ }^{3}$, \\ Ali H. Omar ${ }^{3}$, Samuel LeBlanc ${ }^{2}$, Yohei Shinozuka ${ }^{2}$, John Livingston ${ }^{2}$, Qin Zhang ${ }^{2}$, and Kathleen A. Powell ${ }^{3}$ \\ ${ }^{1}$ NASA Ames Research Center, Moffett Field, CA, USA \\ ${ }^{2}$ Bay Area Environmental Research Institute, Sonoma, CA, USA \\ ${ }^{3}$ NASA Langley Research Center, Hampton, VA, USA \\ ${ }^{4}$ University of Oklahoma, 120 David L. Boren Blvd., Suite 5900, Norman, OK, USA \\ ${ }^{5}$ Science Systems and Applications, Inc., Hampton, VA, USA
}

Correspondence: Meloë S. Kacenelenbogen (meloe.s.kacenelenbogen@ nasa.gov)

Received: 12 October 2018 - Discussion started: 6 November 2018

Revised: 16 March 2019 - Accepted: 18 March 2019 - Published: 12 April 2019

\begin{abstract}
All-sky direct aerosol radiative effects (DARE) play a significant yet still uncertain role in climate. This is partly due to poorly quantified radiative properties of aerosol above clouds (AAC). We compute global estimates of shortwave top-of-atmosphere DARE over opaque water clouds (OWCs), DARE $E_{\text {OWC }}$, using observation-based aerosol and cloud radiative properties from a combination of A-Train satellite sensors and a radiative transfer model. There are three major differences between our DARE OwC calculations and previous studies: (1) we use the depolarization ratio method (DR) on CALIOP (Cloud-Aerosol Lidar with Orthogonal Polarization) Level 1 measurements to compute the AAC frequencies of occurrence and the AAC aerosol optical depths (AODs), thus introducing fewer uncertainties compared to using the CALIOP standard product; (2) we apply our calculations globally, instead of focusing exclusively on regional AAC "hotspots" such as the southeast Atlantic; and (3) instead of the traditional look-up table approach, we use a combination of satellite-based sensors to obtain AAC intensive radiative properties. Our results agree with previous findings on the dominant locations of AAC (south and northeast Pacific, tropical and southeast Atlantic, northern Indian Ocean and northwest Pacific), the season of maximum occurrence and aerosol optical depths (a majority in the 0.01-0.02 range and that can exceed 0.2 at $532 \mathrm{~nm}$ ) across the globe. We find positive averages of global seasonal DARE OWC $_{\text {between }}$ 0.13 and $0.26 \mathrm{~W} \mathrm{~m}^{-2}$ (i.e., a warming effect on climate). Re-
\end{abstract}

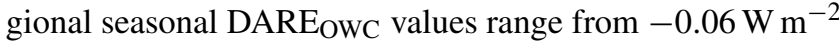
in the Indian Ocean offshore from western Australia (in March-April-May) to $2.87 \mathrm{~W} \mathrm{~m}^{-2}$ in the southeast Atlantic (in September-October-November). High positive values are usually paired with high aerosol optical depths $(>0.1)$ and low single scattering albedos $(<0.94)$, representative of, for example, biomass burning aerosols. Because we use different spatial domains, temporal periods, satellite sensors, detection methods and/or associated uncertainties, the DARE OWC $_{\text {es- }}$ timates in this study are not directly comparable to previous peer-reviewed results. Despite these differences, we empha-

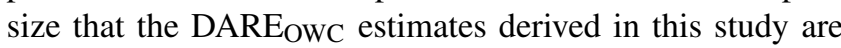
generally higher than previously reported. The primary reasons for our higher estimates are (i) the possible underestimate of the number of dust-dominated AAC cases in our study; (ii) our use of Level 1 CALIOP products (instead of CALIOP Level 2 products in previous studies) for the detection and quantification of AAC aerosol optical depths, which leads to larger estimates of AOD above OWC; and (iii) our use of gridded $4^{\circ} \times 5^{\circ}$ seasonal means of aerosol and cloud

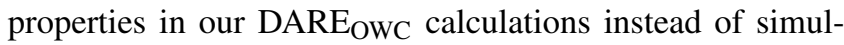
taneously derived aerosol and cloud properties from a combination of A-Train satellite sensors. Each of these areas is explored in depth with detailed discussions that explain both the rationale for our specific approach and the subsequent ramifications for our DARE calculations. 


\section{Introduction}

The direct aerosol radiative effect (DARE) is defined as the change in the upwelling radiative flux $\left(F^{\uparrow}\right)$ at the top of the atmosphere (TOA) due to aerosols. Measured values of DARE depend on the accuracy and the geometry of the observation(s), the concentrations of various atmospheric constituents (e.g., aerosols, clouds and atmospheric gases) and their radiative properties, and the Earth's surface reflectance.

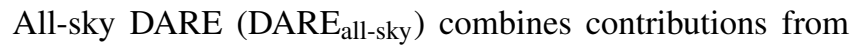

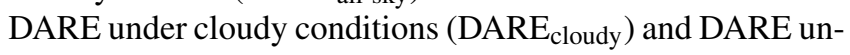
der cloud-free conditions (DARE $E_{\text {non-cloudy }}$ ):

$$
\begin{aligned}
\text { DARE }_{\text {all-sky }}= & \text { DARE }_{\text {cloudy }} \times \text { cloud fraction } \\
& + \text { DARE }_{\text {non-cloudy }} \times(1-\text { cloud fraction })
\end{aligned}
$$

According to $\mathrm{Yu}$ et al. (2006), substantial progress has been made in the assessment of DARE $E_{\text {non-cloudy }}$ using satellite and in situ data. Further evidence is provided in a companion to our study (Redemann et al., 2019), which uses A-Train aerosol observations to constrain DARE $_{\text {non-cloudy }}$ and compares the results with AeroCom (Aerosol Comparisons between Observations and Models) results (see Appendix A for further details). However, traditional passive aerosol remote sensing techniques are limited only to clearsky conditions and significant efforts are required to estimate DARE $E_{\text {cloudy. }}$ Moreover, simulations of DARE from various AeroCom models in Schulz et al. (2006) (see their Fig. 6) show large disparities. Our study focuses on aerosol above cloud (AAC) scenes across the globe and subsequent estimates of DARE $\mathrm{E}_{\text {cloudy }}$ (i.e., the instantaneous shortwave (SW) upwelling TOA reflected radiative fluxes due to clouds only minus SW upwelling TOA fluxes due to clouds with overlying aerosols). Let us note that, ideally,

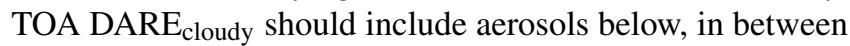
and above clouds. Here we assume that TOA DARE cloudy is only caused by aerosols above clouds. Table 1 lists TOA SW DARE $E_{\text {cloudy }}$ results that use satellite observations in the literature, together with assumptions in their calculations. Compared to the peer-reviewed studies of Table 1, our study marks a departure on three accounts. First, most peer-reviewed DARE $E_{\text {cloudy }}$ calculations focus primarily on the southeast Atlantic (SEAt e.g., Chand et al., 2009; Wilcox et al., 2012; Peters et al., 2011; De Graaf et al., 2012, 2014; Meyer et al., 2013, 2015; Peers et al., 2015; Feng and Christopher, 2015; in Table 1). Second, our results use a combination of A-Train satellite sensors (i.e., MODIS-OMICALIOP), instead of the look-up-table (LUT) approach used in the other studies of Table 1, to obtain estimates of the intensive aerosol radiative properties above clouds. Third, the peer-reviewed global DARE cloudy $_{\text {calculations in Table } 1}$ use standard products from the active satellite sensor CloudAerosol Lidar with Orthogonal Polarization (CALIOP) for either AAC aerosol optical depth (AOD) and/or aerosol and cloud vertical distribution information in the atmosphere
(Zhang et al., 2014, 2016; Matus et al., 2015; Oikawa et al., 2013). In our case, we estimate DARE cloudy $_{\text {globally by us- }}$ ing an alternate method applied to CALIOP Level 1 measurements (Hu et al., 2007b; Chand et al., 2008; Liu et al., 2015) to obtain AAC AOD and the AAC frequency of occurrence. In the sections below, we explain why we have used such a method, instead of other passive or active satellite sensor techniques.

Table 2 lists some passive (i.e., Spinning Enhanced Visible and InfraRed Imager, SEVIRI; Moderate Resolution Imaging Spectroradiometer, MODIS; Polarization and Directionality of Earth's Reflectances, POLDER; Ozone Monitoring Instrument, OMI; or the Scanning Imaging Absorption Spectrometer for Atmospheric Chartography, SCIAMACHY) and active (i.e., CALIOP and CloudSat) satellite sensors that were used to detect and quantify the AAC AODs. Among the peer-reviewed studies of Table 2, those few that present DARE $_{\text {cloudy }}$ results (see Table 1) are denoted by a “+” sign in the first column.

The brightening of clear patches near clouds (Wen et al., 2007) (i.e., "3-D cloud radiative effect" or "cloud adjacency effect") can introduce biases into the current passive satellite AAC retrieval techniques (i.e., lines 1-11 of Table 2). To minimize these biases, this study relies primarily on CALIOP observations (Winker et al., 2009). CALIOP is a three-channel elastic backscatter lidar with a narrow field of view and a narrow source of illuminating radiation, which limits cloud adjacency effects and the subsequent cloud contamination of aerosol data products (Zhang et al., 2005; Wen et al., 2007; Várnai and Marshak, 2009). CALIOP measures high-resolution $(1 / 3 \mathrm{~km}$ in the horizontal and $30 \mathrm{~m}$ in the vertical in low and middle troposphere) profiles of the attenuated backscatter from aerosols and clouds at visible $(532 \mathrm{~nm})$ and near-infrared $(1064 \mathrm{~nm})$ wavelengths along with polarized backscatter in the visible channel (Hunt et al., 2009). These data are distributed as part of the Level 1 CALIOP products. The Level 2 products are derived from the Level 1 products using a succession of sophisticated retrieval algorithms (Winker et al., 2009). The Level 2 processing is composed of a feature detection scheme (Vaughan et al., 2009), a module that classifies features according to layer type (i.e., cloud versus aerosol) (Liu et al., 2010) and subtype (i.e., aerosol species) (Omar et al., 2009), and, finally, an extinction retrieval algorithm (Young and Vaughan, 2009) that retrieves profiles of aerosol backscatter and extinction coefficients and the total column AOD based on modeled values of the extinction-to-backscatter ratio (also called lidar ratio and represented by the symbol $S_{\mathrm{a}}$ ) inferred for each detected aerosol layer subtype.

A few studies use standard CALIOP Level 2 aerosol and cloud layer products to determine AAC occurrence across the globe (see lines 12-21 in Table 2). However, a study by Kacenelenbogen et al. (2014) demonstrates that the standard version 3 CALIOP aerosol products substantially underreport the occurrence frequency of AAC when aerosol opti- 
Table 1. TOA SW DARE $E_{\text {cloudy }}$ calculations that use satellite observations in the literature and specific assumptions in the calculations. See also the theoretical study by Chang and Christopher et al. (2017) (i.e., they impose fixed COD, Re, AOD, aerosol radiative properties, and aerosol/cloud vertical distribution) and the study by Costantino and Bréon et al. (2013) (their method uses MODIS-derived cloud microphysics that are not corrected for overlying aerosols). When not specified, the study uses the standard CALIOP data product; otherwise, it uses the DR (depolarization ratio) or CR (color ratio) technique on CALIOP measurements. MODIS ${ }^{\mathrm{A}}$ and MODIS ${ }^{\mathrm{T}}$ denote the AQUA and TERRA platform respectively. SEAt: southeast Atlantic. LUT: look-up table. See acronyms for satellite sensors MODIS, CALIOP, CloudSat, POLDER, CERES and AMSR-E.

\begin{tabular}{|c|c|c|c|c|c|}
\hline \multirow[t]{2}{*}{ Reference } & \multirow[t]{2}{*}{ Domain } & \multicolumn{4}{|c|}{ Satellite sensor(s) used for DARE cloudy $_{\text {calculations }}$} \\
\hline & & $\begin{array}{l}\text { Cloud properties } \\
\text { (e.g., COD, albedo, } \\
\text { fraction) }\end{array}$ & AOD & $\begin{array}{l}\text { Aerosol radiative prop- } \\
\text { erties (e.g., SSA, g) }\end{array}$ & $\begin{array}{l}\text { Vertical distribution of } \\
\text { aerosol and cloud }\end{array}$ \\
\hline $\begin{array}{l}\text { Chand et } \\
\text { al. (2009) }\end{array}$ & SEAt & MODIS $^{\mathrm{T}}$ & CALIOPCR $^{C}$ & Fixed value & Assumed constant \\
\hline Wilcox (2012) & SEAt & MODIS $^{\mathrm{A}}$, AMSR-E & \multicolumn{3}{|c|}{ CERES provides upwelling shortwave flux } \\
\hline $\begin{array}{l}\text { Peters et } \\
\text { al. }(2011)\end{array}$ & Atlantic & MODIS $^{\mathrm{A}}$, AMSR-E & \multicolumn{3}{|c|}{ CERES provides upwelling shortwave flux } \\
\hline $\begin{array}{l}\text { De Graaf et } \\
\text { al. (2012, } \\
\text { 2014) }\end{array}$ & SEAt & \multicolumn{4}{|c|}{ Direct determination of DARE $\mathrm{Cloudy}_{\text {by building LUT of cloud and aerosol-free reflectances }}$} \\
\hline $\begin{array}{l}\text { Meyer et } \\
\text { al. }(2013)\end{array}$ & SEAt & MODIS $^{\mathrm{A}}$ & CALIOP & LUT approach & CALIOP \\
\hline $\begin{array}{l}\text { Zhang et } \\
\text { al. (2014, } \\
2016)\end{array}$ & Globe & \multicolumn{2}{|c|}{$\begin{array}{c}\text { MODIS }^{\mathrm{A}} \text {, CALIOP (uses probability density } \\
\text { function of CALIOP above-cloud AOD and } \\
\text { underlying MODIS COD) }\end{array}$} & LUT approach & CALIOP \\
\hline $\begin{array}{l}\text { Meyer et } \\
\text { al. }(2015)\end{array}$ & SEAt & \multicolumn{2}{|c|}{$\begin{array}{c}\text { MODIS }^{\mathrm{A}} \text { (simultaneous retrieval of above-cloud } \\
\text { AOD, COD and } R_{\mathrm{e}} \text { ) }\end{array}$} & LUT approach & Assumed constant \\
\hline $\begin{array}{l}\text { Peers et } \\
\text { al. }(2015)\end{array}$ & SEAt & \multicolumn{4}{|c|}{$\begin{array}{l}\text { POLDER (simultaneous retrieval of above-cloud aerosol OD, size and single scattering albedo, cloud } \\
\text { optical depth and cloud top height) }\end{array}$} \\
\hline $\begin{array}{l}\text { Feng and } \\
\text { Christopher } \\
(2015)\end{array}$ & SEAt & MODIS $^{\mathrm{A}}$, CERES & \multicolumn{3}{|c|}{ CERES provides upwelling shortwave flux } \\
\hline $\begin{array}{l}\text { Matus et } \\
\text { al. (2015) }\end{array}$ & Globe & $\begin{array}{l}\text { CloudSat, MODIS }{ }^{\mathrm{A}} \text {, } \\
\text { CALIOP }\end{array}$ & CALIOP & LUT approach & CloudSat, CALIOP \\
\hline $\begin{array}{l}\text { Oikawa et } \\
\text { al. (2013) }\end{array}$ & Globe & CALIOP, MODIS ${ }^{\mathrm{A}}$ & CALIOP & LUT approach & CALIOP \\
\hline This study & Globe & MODIS $^{\mathrm{A}}$ & CALIOP $^{\mathrm{DR}}$ & $\begin{array}{l}\text { MODIS }{ }^{\mathrm{A}}, \text { OMI, } \\
\text { CALIOP }\end{array}$ & Assumed constant \\
\hline
\end{tabular}

cal depths are less than $\sim 0.02$, mostly because these tenuous aerosol layers have attenuated backscatter coefficients less than the CALIOP detection threshold. CALIOP's standard extinction (and optical depth) data products are only retrieved between the tops and bases of detected features, and these boundaries may significantly underestimate the full vertical extent of the layer (Kim et al., 2017; Thorsen et al., 2017; Toth et al., 2018). Furthermore, the Kacenelenbogen et al. (2014) study found essentially no correlation between AAC AOD results reported by the CALIOP and collo- cated NASA Langley airborne high spectral resolution lidar (HSRL). A subsequent study by Liu et al. (2015) shows that the CALIOP Level 2 standard aerosol data products underestimate dust AAC AOD by $\sim 26 \%$ over the tropical Atlantic and smoke AAC AOD by 39\% over the southeast Atlantic.

For these reasons, a few studies in Table 2 (see lines 22 26) use alternate methods on Level 1 CALIOP products, such as the color ratio (CR) (Chand et al., 2008) or the depolarization ratio (DR) (Hu et al., 2007b; Liu et al., 2015) methods, 
Table 2. Studies that observe AAC using passive and active satellite sensors (i.e., from left to right, SEVIRI, POLDER, CloudSat, OMI, MODIS, SCIAMACHY, CALIOP; see Appendix C for acronyms). When using CALIOP, the authors either use the standard Level 2 products (Std), the Depolarization method (DR) (Hu et al., 2007b) or the color ratio method (CR) (Chand et al., 2008). SEAt stands for southeast Atlantic, SEAs for SE Asia, NEAs for NE Asia and TAt for tropical Atlantic.

\begin{tabular}{|c|c|c|c|c|c|c|c|c|c|}
\hline & \multirow[t]{2}{*}{ Reference } & \multirow[t]{2}{*}{ Domain } & \multicolumn{7}{|c|}{ Satellite sensor(s) used for aerosol-above-cloud detection } \\
\hline & & & SEVIRI & POLDER & CloudS & OMI & MODIS & SCIAMA & CALIOP \\
\hline 1 & $\begin{array}{l}\text { Chang and Christopher } \\
\left(2016,2017^{*}\right)\end{array}$ & SEAt & $\mathrm{X}$ & & & & $\mathrm{X}$ & & \\
\hline 2 & Waquet et al. (2013a) & Globe & & $\mathrm{X}$ & & & & & \\
\hline 3 & Waquet et al. $(2009,2013 b)$ & SEAt, TAt & & $\mathrm{X}$ & & & & & \\
\hline 4 & Peers et al. $(2015)^{*}$ & SEAt & & $\mathrm{X}$ & & & & & \\
\hline 5 & Jethva et al $(2013,2014)$ & SEAt, TAt & & & & & $\mathrm{X}$ & & \\
\hline 6 & Torres et al. (2012) & SEAt & & & & $\mathrm{X}$ & & & \\
\hline 7 & Peters et al. $(2011)^{*}$ & Atlantic & & & & $\mathrm{X}$ & & & \\
\hline 8 & De Graaf et al. $(2012,2014)^{*}$ & SEAt & & & & & & $\mathrm{X}$ & \\
\hline 9 & Meyer et al. (2015)* & SEAt & & & & & $\mathrm{X}$ & & \\
\hline 10 & Feng and Christopher $(2015)^{*}$ & SEAt & & & & $\mathrm{X}$ & & & \\
\hline 11 & Sayer et al. (2016) & SEAt, SEAs & & & & & $\mathrm{X}$ & & \\
\hline 12 & Matus et al. $(2015)^{*}$ & Globe & & & $\mathrm{X}$ & & & & Std \\
\hline 13 & Alfaro-Contreras et al. (2016) & Globe & & & & $\mathrm{X}$ & $\mathrm{X}$ & & Std \\
\hline 14 & Alfaro-Contreras et al. (2014) & SEAt, SEAs & & & & $\mathrm{X}$ & $\mathrm{X}$ & & Std \\
\hline 15 & Devasthale and Thomas (2011) & Globe & & & & & & & Std \\
\hline 16 & Yu et al. (2012) & SEAt, TAt & & & & $\mathrm{X}$ & $\mathrm{X}$ & & Std \\
\hline 17 & Wilcox $(2012)^{*}$ & SEAt & & & & $\mathrm{X}$ & & & Std \\
\hline 18 & Meyer et al. $(2013)^{*}$ & SEAt & & & & & & & Std \\
\hline 19 & Zhang et al. $(2014,2016)^{*}$ & Globe & & & & & & & Std \\
\hline 20 & Oikawa et al. $(2013)^{*}$ & Globe & & & & & $\mathrm{X}$ & & Std \\
\hline 21 & Chung et al. (2016) & Globe & & & & & & & Std \\
\hline 22 & Chand et al. (2008) & SEAt & & & & & & & $\mathrm{CR}, \mathrm{DR}$ \\
\hline 23 & Chand et al. (2009)* & SEAt & & & & & & & $\mathrm{CR}$ \\
\hline 24 & Deaconu et al. (2017) & Globe & & & & & & & Std, DR \\
\hline 25 & Liu et al. (2015) & SEAt, TAt & & & & & & & DR \\
\hline 26 & This study* & Globe & & & & & & & $\mathrm{DR}$ \\
\hline
\end{tabular}

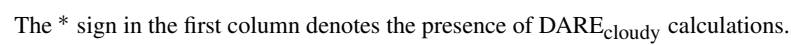

instead of using the AOD reported in the CALIOP standard Level 2 products.

In this study, we use the DR method and a combination of CALIOP Level 1 and Level 2 data products to compute global estimates of the AAC frequency of occurrence (i.e., $\left.f_{\mathrm{AAC}}\right)$ and the AAC AOD (i.e., $\left.\tau_{\mathrm{AAC}}^{\mathrm{DR}}\right)($ Sect. 2.1). We then use CALIOP results of $f_{\mathrm{AAC}}, \tau_{\mathrm{AAC}}^{\mathrm{DR}}$ and other A-Train satel-

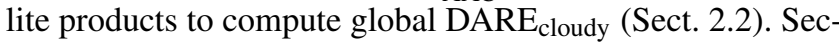
tion 3 describes the geographical and seasonal distribution of global $f_{\text {AAC }}$ (Sect. 3.1), $\tau_{\mathrm{AAC}}^{\mathrm{DR}}$ (Sect. 3.2) and DARE $\mathrm{D}_{\text {cloudy }}$ results (Sect. 3.3). Section 4 revisits some of the limita- 
tions in the method and proposes ways to improve on these DARE $_{\text {cloudy }}$ calculations.

\section{Method}

\subsection{AAC optical depth}

Because the CALIOP backscatter signal is totally attenuated below the lowest "feature" detected within any profile (Vaughan et al., 2009), this lowest feature is defined as being opaque. Approximately $69 \%$ of the time, the opaque feature detected in a profile is the Earth's surface (Guzman et al., 2017). In the remainder of the cases, the opaque feature is either a water cloud, an ice cloud or, very rarely, an aerosol layer.

The DR method, which is also known as the "constrained opaque water cloud method" (Liu et al, 2015), relies on opaque water clouds (OWCs) as reflectivity targets. The OWCs in this study are selected using the five criteria listed in Table B2. Most importantly, (1) only one cloud can be detected within a $5 \mathrm{~km}(15$ shot) along-track average (which means, for example, that marine stratus below thin cirrus are excluded), and (2) this one cloud must be opaque (i.e., lowest feature detected in a column, and not subsequently classified as a surface return). Furthermore, all OWCs must be (3) spatially uniform (i.e., detected at single-shot resolution within every laser pulse included in the $5 \mathrm{~km}$ averaging interval), (4) assigned a high-confidence score by the CALIOP cloud-aerosol discrimination (CAD) algorithm and (5) identified as a high-confidence water cloud by the CALIOP cloud phase identification algorithm. When there is aerosol above OWCs, the lidar backscatter signal received from the underlying water cloud is reduced in direct proportion to the twoway transmittance of the aerosol layer above. However, because the DR retrieval technique requires backscatter measurements from opaque water clouds (Hu et al., 2007b), it cannot be used to retrieve AOD from aerosols lying above the low, transparent water clouds that are frequently observed over remote oceans, especially in the Southern Hemisphere (e.g., Leahy et al., 2012; Mace and Protat, 2018; O et al., 2018).

Based on Hu et al. (2007a, b), Eq. (2) describes how we compute $\tau_{\mathrm{AAC}}^{\mathrm{DR}}$ using the DR method above OWCs.

$\tau_{\mathrm{AAC}}^{\mathrm{DR}}=-0.5 \times \ln \left[\mathrm{IAB}_{\mathrm{SS}, \mathrm{AAC}}^{\mathrm{OWC}} / \mathrm{IAB}_{\mathrm{SS}, \mathrm{CAC}}^{\mathrm{OWC}}\right]$

Here $\mathrm{IAB}_{\mathrm{SS}, \mathrm{AAC}}^{\mathrm{OWC}}$ is the single scattering value (subscript SS) of the layer-integrated attenuated backscatter (IAB) for an OWC underlying one or more aerosol layer(s) above the cloud. $\mathrm{IAB}_{\mathrm{SS}, \mathrm{CAC}}^{\mathrm{OWC}}$ is the single scattering value of the IAB for an OWC underlying clear air above clouds (CAC). By $\mathrm{CAC}$, we mean that there are no aerosols detected above the OWC. In this study, we consider $\tau_{\mathrm{AAC}}^{\mathrm{DR}}$ valid when positive. According to Eq. (2), this means that $\mathrm{IAB}_{\mathrm{SS}, \mathrm{AAC}}^{\mathrm{OWC}}$ needs to always be smaller in magnitude than $\mathrm{IAB}_{\mathrm{SS}, \mathrm{CAC}}^{\mathrm{OWC}}$ and $\tau_{\mathrm{AAC}}^{\mathrm{DR}}$ equals zero when $\mathrm{IAB}_{\mathrm{SS}, \mathrm{AAC}}^{\text {OWC }}$ equals IAB $\mathrm{IBC}_{\mathrm{SS}, \mathrm{CAC}}^{\mathrm{OWC}}$.

Appendix $B$ provides additional information about the application of Eq. (2) and the various steps needed to derive $\tau_{\mathrm{AAC}}^{\mathrm{DR}}$. We list the selection criteria used to identify the OWC dataset in this study and describe the corrections required to obtain single-scattering estimates of IAB from measurements that contain substantial contributions from multiple scattering (Appendix B1). We also describe the technique used for distinguishing between $\mathrm{CAC}$ and AAC conditions (Appendix B2) and illustrate our derivation of an empirical parameterization of $\mathrm{IAB}_{\mathrm{SS}, \mathrm{CAC}}^{\mathrm{OWC}}$ as a global function of latitude and longitude (Appendix B3).

As reported in Table 2, the CALIOP DR method was used to study the African dust transport pathway over the tropical Atlantic (Liu et al., 2015) and the African smoke transport pathway over the southeast Atlantic (Liu et al., 2015; Chand et al., 2008, 2009). More recently, the CALIOP DR method was also used by Deaconu et al. (2017) to assess POLDER AAC AOD values (Waquet et al., 2009, 2013b; Peers et al., 2015) across the globe. In this study, we extend the previous regional studies of Liu et al. (2015) and Chand et al. (2008, $2009)$ to derive global CALIOP-based AAC AOD estimates. Let us note that, in our study, the accuracy of $\tau_{\mathrm{AAC}}^{\mathrm{DR}}$ depends on measurements of targets of very high signal-to-noise ratio (SNR) such as OWCs in clear skies and OWCs underlying aerosol layers.

\subsection{AAC direct aerosol radiative effects}

Having first retrieved global values of $\tau_{\mathrm{AAC}}^{\mathrm{DR}}$ from the CALIOP measurements, we then compute global estimates

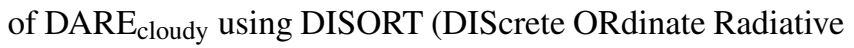
Transfer; Stamnes et al., 1988; Buras et al., 2011), a sixstream plane-parallel radiative transfer model with molecular absorption characterized by a correlated- $k$ distribution scheme (Fu and Liou, 1992) that is embedded within the LibRadtran Radiative Transfer (RT) package (Emde et al., 2016). Hereafter, our seasonally and spatially gridded $\left(4^{\circ} \times\right.$ $5^{\circ}$ ) averaged $\mathrm{SW}(250$ to $5600 \mathrm{~nm}$ ) global TOA DARE $\mathrm{Eloudy}$ results will be called DARE OWC $_{\text {, }}$ as they pertain to a specific category of clouds (i.e., OWCs) defined according to the CALIOP data selection criteria set forth in Table B2. We list the following input parameters to DISORT in order to derive estimates of DARE OwC:

1. Atmospheric profiles of pressure, temperature, air density, ozone, water vapor, $\mathrm{CO}_{2}$ and $\mathrm{NO}_{2}$ use standard US atmosphere profiles (Anderson et al., 1986).

2. Aerosol intensive radiative properties (i.e., properties that depend solely on aerosol species and are unrelated to the aerosol amount) are informed by seasonal maps $\left(4^{\circ} \times 5^{\circ}\right.$, daytime in 2007) of combined MODIS-OMICALIOP (MOC) retrieved median spectral extinction coefficients, single scattering albedos and asymmetry 
parameters at 30 different wavelengths. As an example, Fig. A1 in the Appendix shows the seasonal maps of MOC SSA at $546.3 \mathrm{~nm}$ that were used in the calculation of DARE OwC. These MOC retrievals, described in Appendix A, are the basis of a companion study (Redemann et al., 2019). Let us note that we only use the shape of the MOC extinction coefficient spectrum and not its actual magnitude; the MOC spectral extinction coefficient spectra is normalized to the seasonal 2008-2012 average value of either $\tau_{\mathrm{AAC}}^{\mathrm{DR}}$ or $\tau_{\mathrm{AAC}}^{\mathrm{DR}} \times f_{\mathrm{AAC}}$ within each grid cell. Our method assumes similar aerosol radiative properties above clouds and in nearby clear-sky regions.

3. Aerosol extensive radiative properties (i.e., properties that depend on the aerosol amount present in the atmosphere) are informed by seasonal maps $\left(4^{\circ} \times 5^{\circ}\right.$, nighttime from 2008 to 2012) of either CALIOP $\tau_{\mathrm{AAC}}^{\mathrm{DR}}$ (see Eq. 2) or CALIOP $\tau_{\mathrm{AAC}}^{\mathrm{DR}} \times f_{\mathrm{AAC}}$. We chose to use nighttime CALIOP $\tau_{\mathrm{AAC}}^{\mathrm{DR}}$ or $\tau_{\mathrm{AAC}}^{\mathrm{DR}} \times f_{\mathrm{AAC}}$ results in the estimation of DARE OWC because, at nighttime, the CALIOP SNR is not affected by ambient solar background and leads to a more accurate measurement of the aerosol signal (compared to daytime). By doing this, we implicitly chose a better accuracy in the aerosol extensive radiative properties over a temporal overlap between aerosol extensive (nighttime) and intensive (daytime) radiative properties.

4. Cloud albedos are computed from cloud droplet effective radius $\left(R_{\mathrm{e}}\right)$ and cloud optical depth (COD) information inferred from MODIS averaged monthly $1^{\circ} \times 1^{\circ}$ grids (i.e., liquid water cloud products of MYD08_M3: "Cloud Effective Radius Liquid Mean Mean" and "Cloud Optical Thickness Liquid Mean Mean", Platnick 2015) from 2008 to 2012 (see Eqs. 1-9 of Peng et al., 2002). These maps are then further gridded (to $4^{\circ} \times 5^{\circ}$ ) and seasonally averaged to match the format of the aerosol radiative properties. Figure A2 shows the seasonal maps of MODIS COD that were used in the calculation of DARE OwC.

5. Aerosol and cloud layer heights are assumed constant across the globe (between 3-4 and 2-3 km respectively in this study), similar to other studies in Table 1 (e.g., Meyer et al., 2015).

6. Earth's surface albedo uses global gap-filled Terra and Aqua combined MODIS BRDF-albedo products. It uses the 16-day closest product (i.e., MCD43GF) to the middle of each season (i.e., 15 January for DJF, 15 April for MAM, 15 July for JJA and 15 October for SON). In the open ocean, the Cox and Munk (1954) sea surface albedo parameterization is applied with a wind speed of $10 \mathrm{~m} \mathrm{~s}^{-1}$.

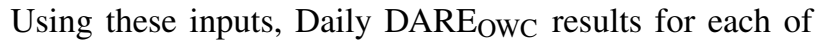
the $4^{\circ} \times 5^{\circ}$ grid cells are obtained by averaging 24 LibRadtran RT calculations, corresponding to 24 different sun positions at each hour of the day.

\section{Results}

\subsection{AAC occurrence frequencies}

To provide the necessary context for interpreting our TOA radiative transfer calculations, we first establish the observational AAC occurrence frequencies from which we will subsequently compute estimates of DARE ${ }_{\text {OWC. }}$ Figure 1 illustrates the annual gridded mean (5 years) global occurrence frequencies of single-layer clouds (panel a), opaque water clouds that are suitable for the DR method (panel b) and aerosol-above-clouds cases using the DR method (panel c). Figure 1d shows the difference between the number of AAC cases using the DR method (i.e., number of cases with $\left.\tau_{\mathrm{AAC}}^{\mathrm{DR}}>0\right)$ and the number of AAC cases using the standard Version 3 CALIOP product.

Uniform single-layer clouds (i.e., $\mathrm{C} 1-\mathrm{C} 3$ of Table B2) are detected in $\sim 47 \%$ of all $5 \mathrm{~km}$ CALIOP samples across the globe (see Fig. 1a). In other words, at any one time, approximately half of the globe is covered by uniform single-layer clouds. As expected, the highest occurrence of those clouds is in the high- and low-latitude bands and especially over the southern oceans. According to Fig. 1b, OWCs suitable for the DR method (i.e., C1-C5 of Table B2) are mostly in the marine stratocumulus regions and represent a mean of $7 \%$ of all $5 \mathrm{~km}$ CALIOP samples across the globe. This significant reduction from half-the-globe coverage is explained by the five criteria used to select OWCs for the application of the DR method (i.e., C1-C5 of Table B2). The highest occurrence of OWCs can be found offshore from the west coasts of North and South America, southwest Africa and Australia. In particular, OWC cover ranges from $60 \%$ to $75 \%$ over the region of the southeast Atlantic in August (Klein and Hartmann, 1993). Also, the southeastern Pacific region off the Peruvian and Chilean coasts is the location of the largest and most persistent stratocumulus deck in the world (Klein and Hartmann, 1993). The percentage of AAC cases (i.e., AAC cases showing positive $\tau_{\mathrm{AAC}}^{\mathrm{DR}}$ ) at the basis of our study is very small compared to the total number of $5 \mathrm{~km}$ CALIOP profiles per grid cell (i.e., mean of $5 \%$ in Fig. 1c). This is primarily due to a small number of low OWC used for the DR method across the globe (when comparing Fig. 1a and b).

Figure 1d illustrates the difference in occurrence frequencies of AAC cases using the DR method compared to the standard Version 3 CALIOP product. Negative values, shown in blue, indicate the fraction of cases for which the DR method fails to detect above-cloud aerosols that are reported in the standard CALIOP product. Similarly, positive values, shown in red, indicate the number of cases for which above- 

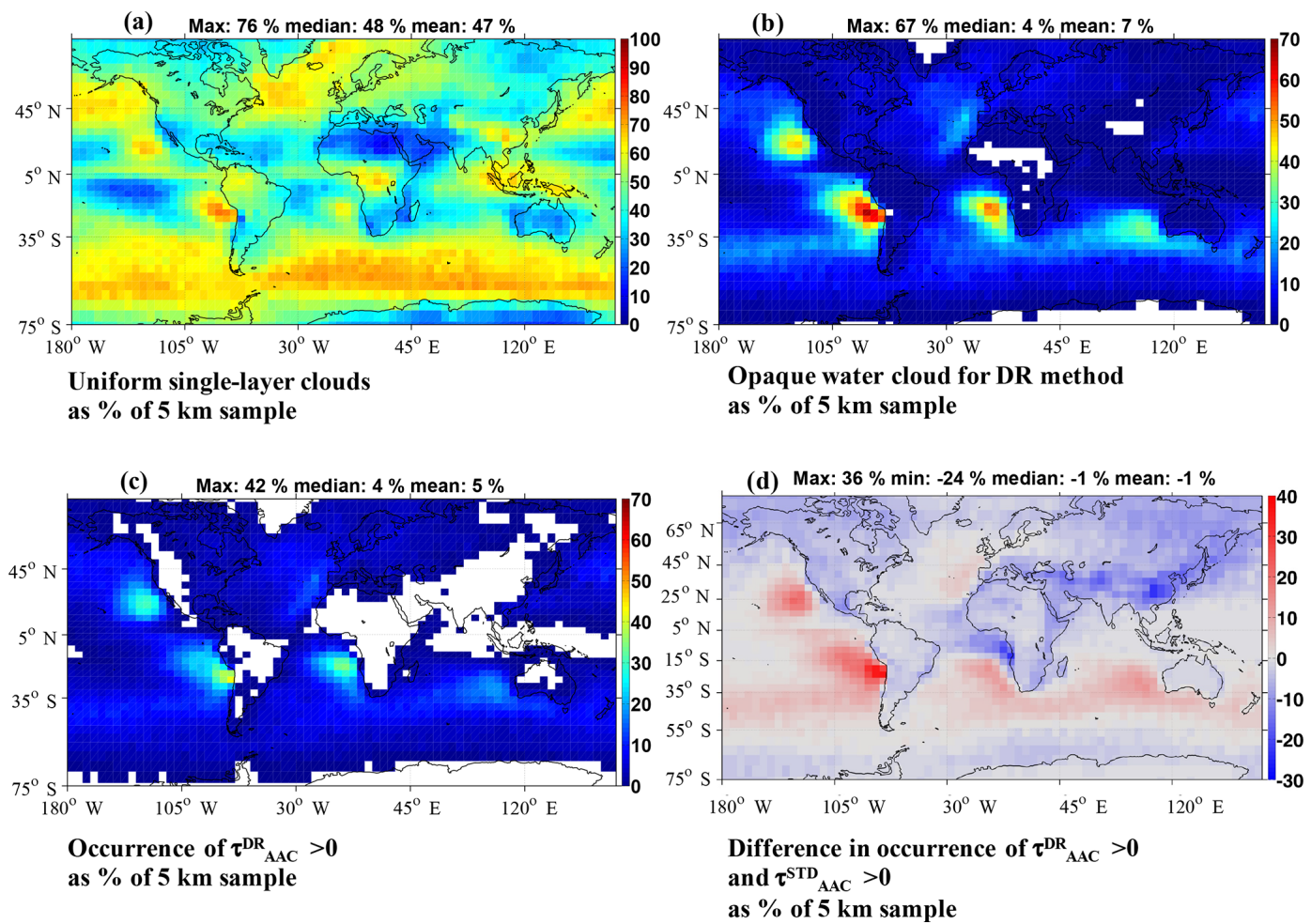

Figure 1. During nighttime, from 2008 to 2012 on a $4^{\circ} \times 5^{\circ}$ grid: occurrence frequencies of (a) uniform single-layer clouds (C1-C3 of Table B2), (b) opaque water clouds suitable for the DR method (C1-C5 of Table B2; these clouds can be obstructed or unobstructed) and (c) AAC cases that show a positive $\tau_{\mathrm{AAC}}^{\mathrm{DR}}$ at $532 \mathrm{~nm}$. Panel (d) shows the difference between the number of AAC cases using the DR method (i.e., number of cases with $\tau_{\mathrm{AAC}}^{\mathrm{DR}}>0$ ) and the number of AAC cases using the standard Version 3 CALIOP product (i.e., number of cases with $\tau_{\mathrm{AAC}}^{\mathrm{STD}}>0$ ); CALIOP AAC cases using the standard algorithm are defined as $5 \mathrm{~km}$ columns showing an uppermost layer classified as aerosols and a cloud layer anywhere below that aerosol layer; the cloud itself does not have to satisfy any of the criteria of Table B2. Grid cells are $4^{\circ} \times 5^{\circ}$ latitude-longitude. The percentages in (a)-(d) use the number of $5 \mathrm{~km}$ CALIOP samples within each grid cell as a reference. White pixels show either no CALIOP observations, no CALIOP OWC detection, a small number of CALIOP unobstructed OWCs or a small number of positive $\tau_{\mathrm{AAC}}^{\mathrm{DR}}$ values. The title of each map shows the global maximum, median and mean values.

cloud aerosols are detected by the DR method but not reported in the standard CALIOP data product. Unlike the AAC cases detected using the DR method, the AAC cases obtained from the CALIOP standard product do not impose any restrictions on the nature of the underlying clouds. Instead, the CALIOP standard product reports aerosol detected above both opaque and transparent clouds, irrespective of cloud thermodynamic phase. The blue regions in Fig. 1d show that, relative to the CALIOP standard product, our implementation of the DR method could be failing to detect AAC cases over most of the land surfaces and over the Arabian Sea, the tropical Atlantic and the southeast Atlantic regions. The lack of AAC cases offshore from the southwest coast of Africa in the DR method dataset is the result of our conservative data filtering strategy. Because the IABs of aerosol-contaminated OWCs can differ significantly from those measured in pristine, aerosol-free conditions, OWCs suspected of being aerosol-contaminated (which are ubiquitous in this part of the world and very common over continents) are specifically excluded from our DR method analy- ses (see Appendix B3 for more details). However, some regions such as the NE and SE Pacific exhibit up to $40 \%$ more AAC cases when using the DR method. The SE Pacific region, especially offshore from Chile, shows particularly tenuous aerosols, with attenuated backscatter values that typically fall below the CALIOP detection limit, thus hampering the detection of AAC using the standard CALIOP algorithm (Kacenelenbogen et al., 2014).

In the rest of this study, the frequency of occurrence of AAC, $f_{\mathrm{AAC}}$, is defined as follows:

$f_{\mathrm{AAC}}=N_{\mathrm{AAC}} / N_{\mathrm{OWC}}$,

where $N_{\mathrm{AAC}}$ is the number of AAC cases (i.e., cases showing a positive $\tau_{\mathrm{AAC}}^{\mathrm{DR}}$ at $532 \mathrm{~nm}$ ) and $N_{\mathrm{OWC}}$ is the number of OWCs within each $4^{\circ} \times 5^{\circ}$ grid cell. Let us note that different studies use different references when computing the frequency of occurrence of AAC. The definition in Eq. (3) is similar to the one in Zhang et al. (2016) (see their Eq. 1) and different from Devasthale and Thomas (2011), where $f_{\mathrm{AAC}}$ 
is defined as the ratio of AAC cases to the total number of CALIOP observations (similar to what is shown in Fig. 1c).

Figure 2 illustrates the global seasonal $f_{\text {AAC }}$ (see Eq. 3) from 2008 to 2012 . We find a median global $f_{\text {AAC }}$ of $58 \%$ to $61 \%$ with regional values that can reach more than $80 \%$ in some regions such as the southeast Atlantic, especially during the JJA season. The AAC occurrence frequencies in Fig. 2 generally agree with previous findings (Zhang et al., 2016; Devasthale and Thomas, 2011) on the location and season of highest $f_{\mathrm{AAC}}$.

\subsection{AAC optical depths}

Figure 3 introduces the global, nighttime and multiyear (2008-2012) AAC optical depths ( $\tau_{\mathrm{AAC}}^{\mathrm{DR}}$; see Eq. 2 ) dataset that was computed in this study.

About $40 \%$ (i.e., 2.2 million data points) of the initial dataset (i.e., $N \sim 5.6$ million) shows negative $\tau_{\mathrm{AAC}}^{\mathrm{DR}}$ values and were flagged as invalid data (see grey values in Fig. 3). When looking at all valid (i.e., positive) $\tau_{\mathrm{AAC}}^{\mathrm{DR}}$ values (blue), we show a majority of very small $\tau_{\mathrm{AAC}}^{\mathrm{DR}}$ values in the $0.01-$ 0.02 AOD range. This agrees with the findings of Devasthale and Thomas (2011). Let us note that averaging all data points per $4^{\circ} \times 5^{\circ}$ grid cell (instead of the native resolution shown in Fig. 3) increases the AOD bin of maximum AAC occurrence globally from 0.01 (Fig. 3) to 0.03 .

Table 3 shows four different ways of computing global seasonal and annual averages of aerosol optical depth above clouds: we use either $\tau_{\mathrm{AAC}}^{\mathrm{DR}}$ or $\tau_{\mathrm{AAC}}^{\mathrm{DR}} \times f_{\mathrm{AAC}}$ (see Case I-II or III-IV) and then either (i) exclude all cases of $\tau_{\mathrm{AAC}}^{\mathrm{DR}}<0$ from the average (i.e., as in Case I and Case III), or (ii) set all cases of $\tau_{\mathrm{AAC}}^{\mathrm{DR}}<0$ to zero, and include these samples in the averages (i.e., as in Case II and IV). Let us note that using $\tau_{\mathrm{AAC}}^{\mathrm{DR}} \times f_{\mathrm{AAC}}$ (instead of $\tau_{\mathrm{AAC}}^{\mathrm{DR}}$ ) acknowledges the fact that some OWCs present no overlying aerosols. In this case, we assume that when the DR technique retrieves an invalid AAC measurement, $f_{\mathrm{AAC}}=0$ and there are no aerosols above the cloud.

Figure 4 shows global seasonal nighttime median $\tau_{\mathrm{AAC}}^{\mathrm{DR}} \times$ $f_{\text {AAC }}$ from 2008 to 2012 (i.e., as in Case III of Table 3). The title of each seasonal map (DJF, MAM, JJA, SON respectively) in Fig. 4 shows the global maximum $(0.11,0.13,0.22$, 0.20 respectively), median (0.02 for all seasons) and mean (0.03 in DJF, MAM and SON and 0.04 in JJA) $\tau_{\mathrm{AAC}}^{\mathrm{DR}} \times f_{\mathrm{AAC}}$ values.

We do not expect the $\tau_{\mathrm{AAC}}^{\mathrm{DR}} \times f_{\mathrm{AAC}}$ values of Fig. 4 to be similar to the results of Zhang et al. (2014), Devasthale and Thomas (2011), Alfaro-Contreras et al. (2016) or Yu and Zhang (2013) (see Table 2) as these studies use standard CALIOP Level 2 aerosol and cloud layer products for AAC observations, instead of using the DR method. On the other hand, the results of Fig. 4 seem to be in qualitative agreement with the global AAC AOD derived from spaceborne POLDER observations (Waquet et al., 2013a). Let us note that Waquet et al. (2013a) have to assume an underly- ing COD larger than 3 to ensure the saturation of the polarized light scattered by the cloud layer. Although Deaconu et al. (2017) make different assumptions in the application of the DR method on CALIOP measurements (e.g., they impose a constant cloud lidar ratio for OWCs with clear air above), they find that POLDER and CALIOP $\tau_{\mathrm{AAC}}^{\mathrm{DR}}$ are in good agreement over the southeast Atlantic $\left(R^{2}=0.83\right)$ and over the tropical Atlantic $\left(R^{2}=0.82\right)$ from May to October 2008.

\subsection{AAC direct aerosol radiative effects}

\subsubsection{Global results of DARE OWC $_{\text {DW }}$}

Figure 5 shows the seasonal TOA SW DARE OWC $_{\text {estimates }}$ $\left(\mathrm{W} \mathrm{m}^{-2}\right)$ that use CALIOP $\tau_{\mathrm{AAC}}^{\mathrm{DR}} \times f_{\mathrm{AAC}}$ (see Fig. 4 ) as input to a radiative transfer model, together with the other param-

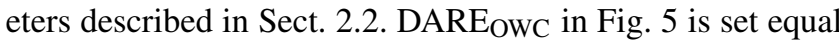

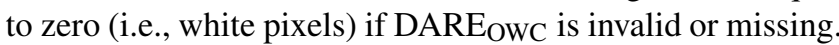

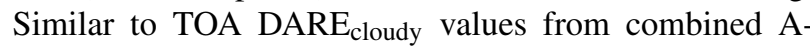
Train satellites in Oikawa et al. (2013) (see their Fig. 10) and from general circulation models (GCMs) (e.g., SPRINTARS) in Shulz et al. (2006) (see their Figs. 6 and 7), TOA DARE $_{\text {OWC }}$ values in Fig. 5 are mostly positive (i.e., a warming effect due to less energy leaving the climate system) across the globe. We find, globally, $72 \%$ positive $4^{\circ} \times 5^{\circ}$ DARE $_{\text {OWC }}$ values (i.e., $N=4045$ ) against $28 \%$ negative values (i.e., $N=1581$ ) when considering all four seasons in Fig. 5. On the other hand, the highest negative TOA DARE $_{\text {OWC }}$ values in Fig. 5 (i.e., cooling effects shown in green pixels) are over the tropical Atlantic (in MAM, JJA and SON), in the Pacific Ocean offshore from Mexico (in JJA) and at the periphery of the Arabian Sea (in JJA).

There are multiple ways to compute the global seasonal and annual DARE cloudy $_{\text {averages (i.e., DARE }}$ OwC in our case), and it is not clear which method would bring us closer to the true DARE $E_{\text {cloudy }}$ state of the planet. For this reason, we list several different methods in Table 4. We either use CALIOP $\tau_{\mathrm{AAC}}^{\mathrm{DR}}$ or CALIOP $\tau_{\mathrm{AAC}}^{\mathrm{DR}} \times f_{\mathrm{AAC}}$ (Case I-II or IIIIV) and we either exclude invalid DARE $E_{\text {OWC }}$ values or set invalid DARE $\mathrm{OWC}_{\mathrm{O}}=0$ (Case I-III or II-IV). For completeness and as an intermediate step towards DARE $E_{\text {all-sky }}$ (see Eq. 1), Case V and VI show the global seasonal averages of DARE $E_{O W C} \times$ cloud fraction $(C F)$, instead of DARE $E_{O W C}$. The CF values use monthly MODIS AQUA MYD08_M3 products (variable "Cloud_Retrieval_Fraction_Liquid_FMean"), which are seasonally averaged and gridded to $4^{\circ} \times 5^{\circ}$.

Global seasonal and annual DARE OWC $_{\text {averages (see titles }}$ in Fig. 5 and Table 4) in our study represent the surface area of each grid cell. Each valid DARE $E_{\text {OWC }}$ value per pixel on each map of Fig. 5 is multiplied by the surface of the pixel. These values per grid cell are then summed up and divided by the sum of the surface of all valid grid cells.

Figure 5 corresponds to the setting of Case IV in Table 4. The reason why we have decided to showcase this setting is 

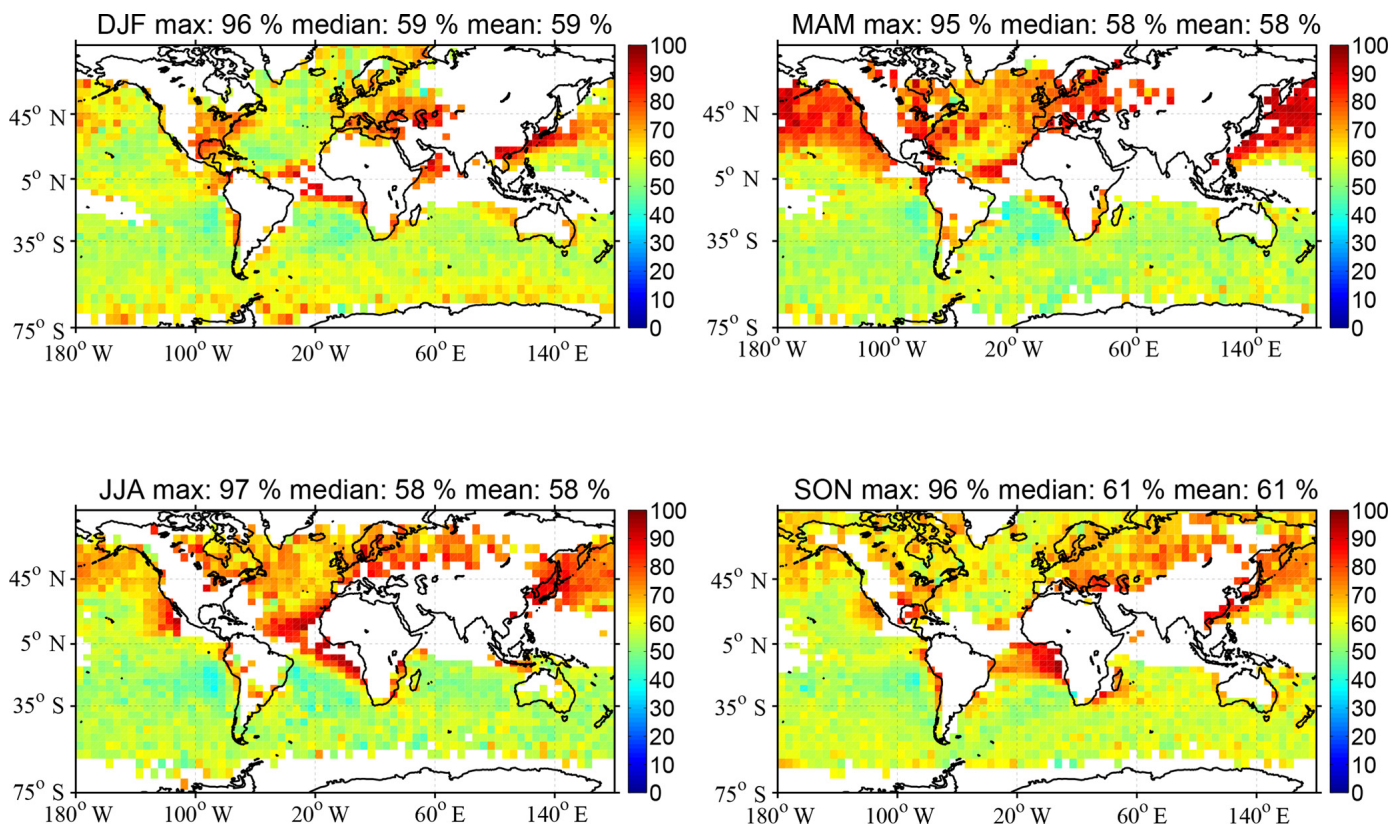

Figure 2. Global seasonal $4^{\circ} \times 5^{\circ}$ nighttime AAC occurrence frequency (noted $f_{\text {AAC }}$; see Eq. 3) from 2008 to 2012 . White pixels show either no CALIOP observations, a limited number of CALIOP unobstructed OWCs or a limited number of positive $\tau_{\mathrm{AAC}}^{\mathrm{DR}}$ values. White pixels are not considered in the global mean and median $f_{\mathrm{AAC}}$ values in the title of each map. The title of each map shows the global maximum, median and mean values.

Table 3. Global seasonal and annual averages of $\tau_{\mathrm{AAC}}^{\mathrm{DR}}$ (Case I and II) or $\tau_{\mathrm{AAC}}^{\mathrm{DR}} \times f_{\mathrm{AAC}}$ (Case III and IV) when assuming either (i) $\tau_{\mathrm{AAC}}^{\mathrm{DR}}<0$ cases are excluded from the averages (Case I and III) or (ii) $\tau_{\mathrm{AAC}}^{\mathrm{DR}}<0$ cases are set to zero and included in the averages (Case II and IV). Annual averages here (last column) are the mean of the seasonal averages.

\begin{tabular}{lrrrrr}
\hline Global mean aerosol optical depth & DJF & MAM & JJA & SON & Annual \\
\hline Case I: $\tau_{\mathrm{AAC}}^{\mathrm{DR}}$, invalid $\tau_{\mathrm{AAC}}^{\mathrm{DR}}$ excluded & 0.04 & 0.05 & 0.05 & 0.05 & 0.05 \\
\hline Case II: $\tau_{\mathrm{AAC}}^{\mathrm{DR}}$, invalid $\tau_{\mathrm{AAC}}^{\mathrm{DR}}=0$ & 0.02 & 0.02 & 0.02 & 0.02 & 0.02 \\
\hline Case III: $\tau_{\mathrm{AAC}}^{\mathrm{DR}} \times f_{\mathrm{AAC}}$, invalid $\tau_{\mathrm{AAC}}^{\mathrm{DR}}$ excluded & 0.03 & 0.03 & 0.04 & 0.03 & 0.03 \\
\hline Case IV: $\tau_{\mathrm{AAC}}^{\mathrm{DR}} \times f_{\mathrm{AAC}}$, invalid $\tau_{\mathrm{AAC}}^{\mathrm{DR}} \times f_{\mathrm{AAC}}=0$ & 0.01 & 0.01 & 0.01 & 0.01 & 0.01 \\
\hline
\end{tabular}

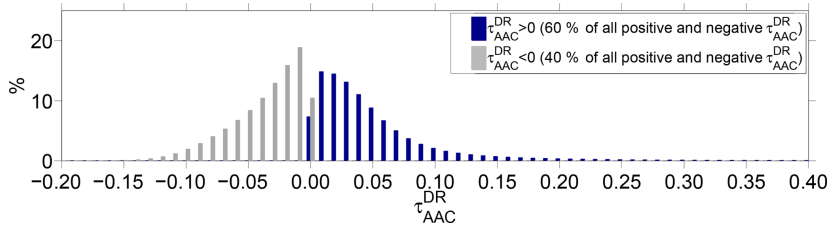

Figure 3. Global distribution of $\tau_{\mathrm{AAC}}^{\mathrm{DR}}$ at $532 \mathrm{~nm}$. Positive (i.e., valid) $\tau_{\mathrm{AAC}}^{\mathrm{DR}}$ values are in dark blue $(N \sim 3.4$ million $)$ and negative $\tau_{\mathrm{AAC}}^{\mathrm{DR}}$ values in grey $(N \sim 2.2$ million). These are nighttime CALIOP measurements from 2008 to 2012.

because it closely resembles the settings of the DARE $\mathrm{E}_{\text {cloudy }}$ calculations in Zhang et al. (2016); i.e., it assumes DARE $=0$ when CALIOP cannot detect an aerosol layer. Figure 5 shows positive global seasonal DARE $\mathrm{OWC}_{\mathrm{W}}$ averages between 0.13 and $0.26 \mathrm{~W} \mathrm{~m}^{-2}$ (and an annual average of $0.20 \mathrm{~W} \mathrm{~m}^{-2}$ in Table 4) as well as the lowest DARE OwC values when com-

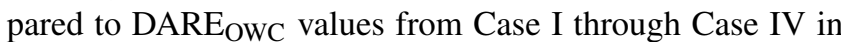
Table 4. These values are nonetheless much larger than the global annual ocean DARE cloudy $_{\text {values reported in Zhang }}$ et al. (2016) and Schulz et al. (2006) (e.g., annual average of $0.015 \mathrm{~W} \mathrm{~m}^{-2}$ reported over ocean in Zhang et al., 2016). Moreover, Matus et al. (2015) find (see their Table 2)

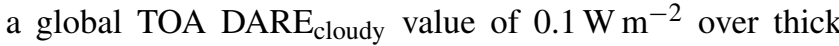
clouds (these clouds are similar to our study), compensated by a global TOA DARE $E_{\text {cloudy }}$ value of $-2 \mathrm{~W} \mathrm{~m}^{-2}$ over thin clouds.

Section 3.3.2 further analyzes DARE ${ }_{\text {OWC }}$, together with $f_{\mathrm{AAC}}, \tau_{\mathrm{AAC}}^{\mathrm{DR}}, \mathrm{SSA}$ and COD results in a few selected regions and compares these results to previous studies. 

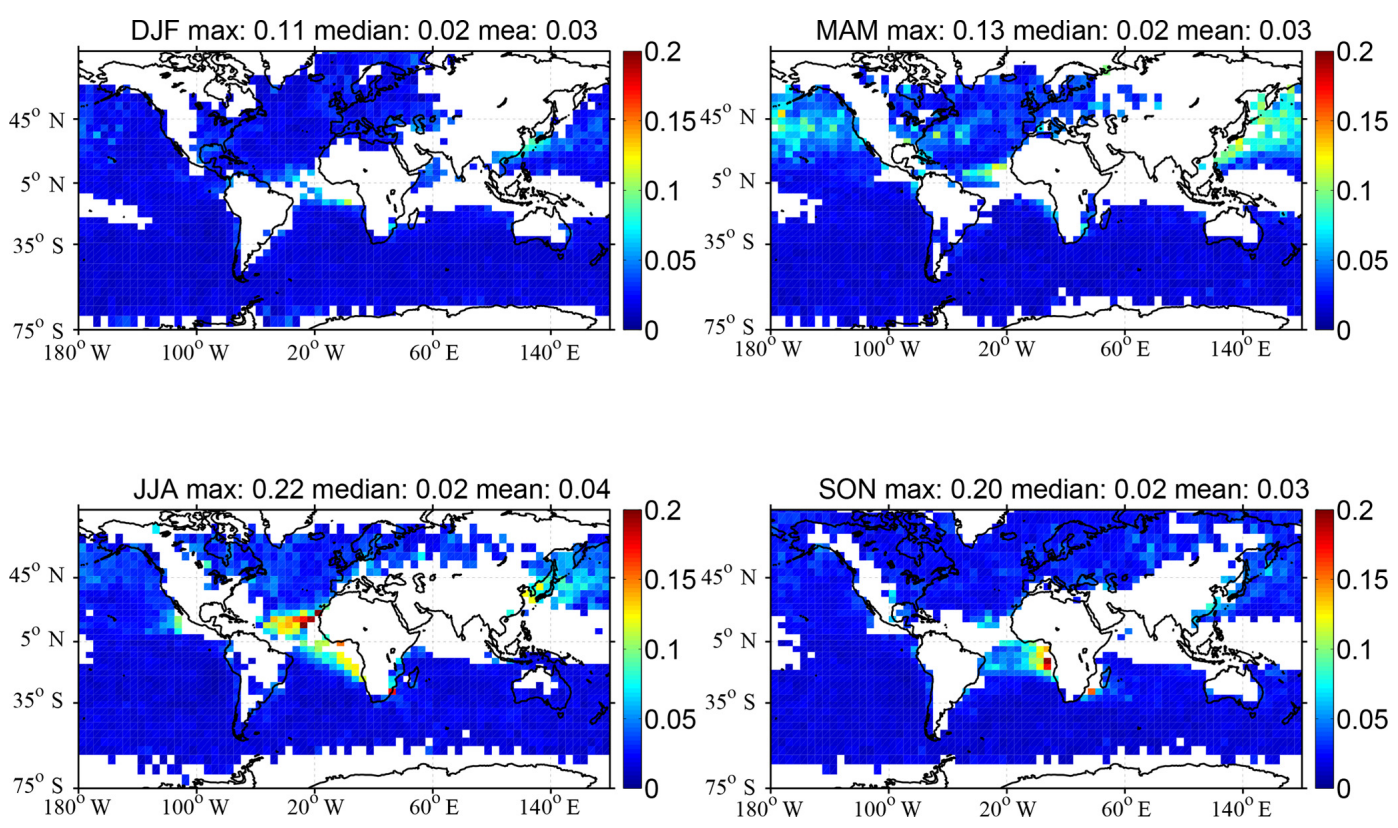

Figure 4. Global seasonal $4^{\circ} \times 5^{\circ}$ nighttime median $\tau_{\mathrm{AAC}}^{\mathrm{DR}} \times f_{\mathrm{AAC}}$ from 2008 to 2012 . Underlying clouds satisfy the criteria in Table $\mathrm{B} 2$. White pixels show either no CALIOP observations, a limited number of CALIOP unobstructed OWCs or a limited number of positive $\tau_{\mathrm{AAC}}^{\mathrm{DR}}$ values. White pixels are not included when calculating the global mean and median $\tau_{\mathrm{AAC}}^{\mathrm{DR}}$ values in the title of each map (i.e., as in Case III in Table 3). Note that if the white pixels were set equal to zero, the seasonal and annual global $\tau_{\mathrm{AAC}}^{\mathrm{DR}}$ values would correspond to Case IV in Table 3. The title of each map shows the global maximum, median and mean values.
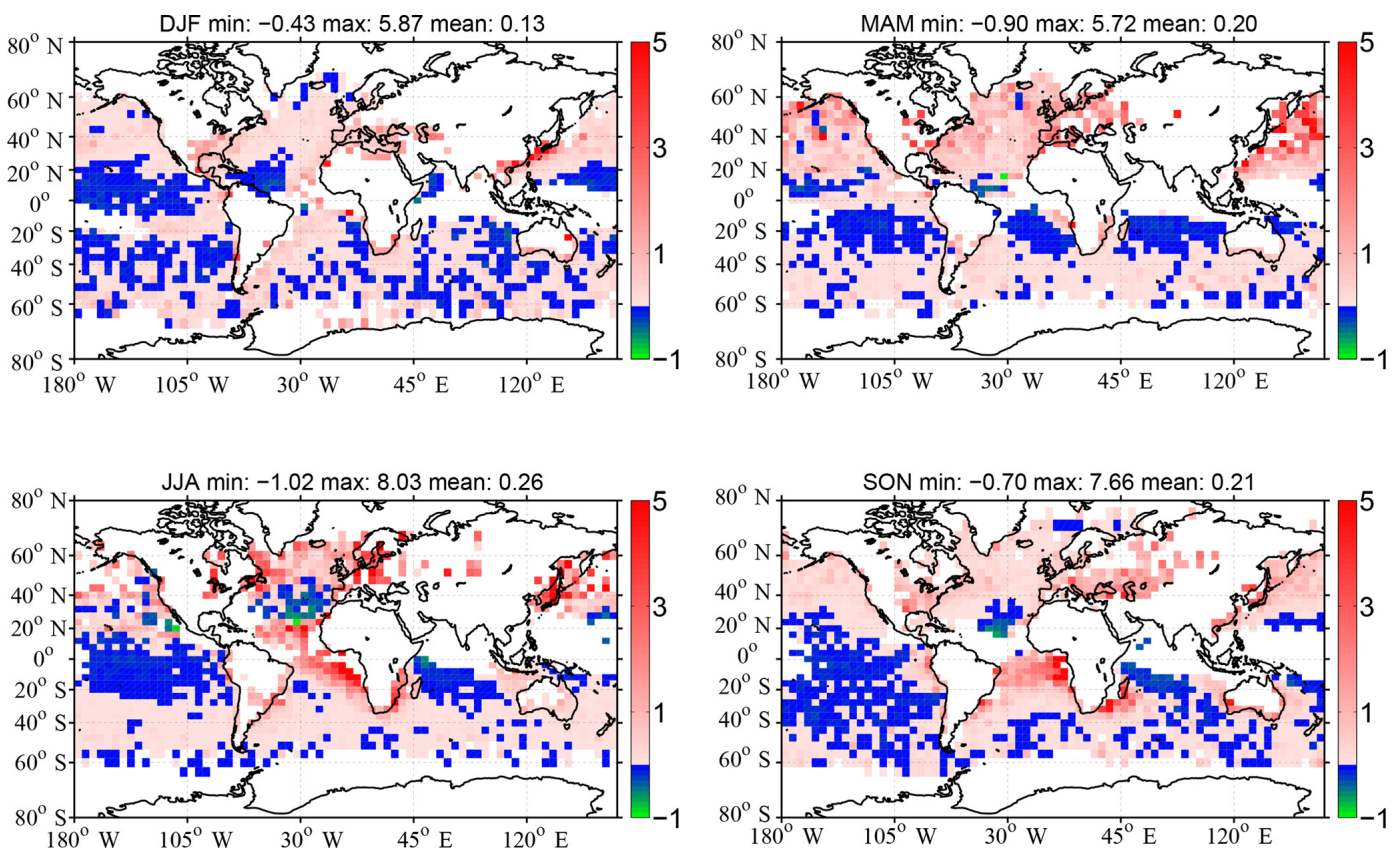

Figure 5. Global seasonal $4^{\circ} \times 5^{\circ}$ TOA SW DARE $\mathrm{OWC}$ estimates $\left(\mathrm{W} \mathrm{m}^{-2}\right.$, as described in Sect. 2.2). A white pixel is counted as $\mathrm{DARE}_{\mathrm{OWC}}=0$ in the global mean DARE $\mathrm{OWC}$ values in the title of each map. White pixels show a limited number of CALIOP OWCs, positive $\tau_{\mathrm{AAC}}^{\mathrm{DR}}$ values or auxiliary MODIS-OMI-CALIOP combined satellite observations. The title of each map shows the global minimum, maximum and mean values. 
Table 4. Global seasonal and annual averages of TOA SW DARE $O$ WC estimates ( $\mathrm{W} \mathrm{m}^{-2}$, as described in Sect. 2.2). Annual averages (last column) are the mean of the seasonal averages (e.g., 0.53 for Case I is the average of $0.34,0.52,0.71$ and 0.56 ); CF stands for cloud fraction.

\begin{tabular}{|c|c|c|c|c|c|}
\hline Global averaged DARE & DJF & MAM & JJA & SON & Annual \\
\hline Case I: DARE ${ }_{\text {OWC }}, \tau_{\mathrm{AAC}}^{\mathrm{DR}}$, invalid DARE $\mathrm{OWC}_{\mathrm{O}}$ excluded & 0.34 & 0.52 & 0.71 & 0.56 & 0.53 \\
\hline Case II: DARE ${ }_{\mathrm{OWC}}, \tau_{\mathrm{AAC}}^{\mathrm{DR}}$, invalid DARE $\mathrm{OWC}=0$ & 0.19 & 0.26 & 0.35 & 0.29 & 0.27 \\
\hline Case III: DARE $\mathrm{OWC}, \tau_{\mathrm{AAC}}^{\mathrm{DR}} \times f_{\mathrm{AAC}}$, invalid DARE $\mathrm{OWC}_{\mathrm{C}}$ excluded & 0.24 & 0.40 & 0.53 & 0.40 & 0.39 \\
\hline Case IV: DARE ${ }_{\text {OWC }}, \tau_{\mathrm{AAC}}^{\mathrm{DR}} \times f_{\mathrm{AAC}}$, invalid $\mathrm{DARE}_{\mathrm{OWC}}=0$ & 0.13 & 0.20 & 0.26 & 0.21 & 0.20 \\
\hline Case V: DARE ${ }_{O W C} \times C F, \tau_{A A C}^{D R}$, invalid DARE $E_{\text {OWC }}$ excluded & 0.11 & 0.16 & 0.25 & 0.19 & 0.18 \\
\hline Case VI: DARE ${ }_{\mathrm{OWC}} \times \mathrm{CF}, \tau_{\mathrm{AAC}}^{\mathrm{DR}} \times f_{\mathrm{AAC}}$, invalid DARE $\mathrm{OWC}=0$ & 0.04 & 0.06 & 0.09 & 0.07 & 0.07 \\
\hline
\end{tabular}

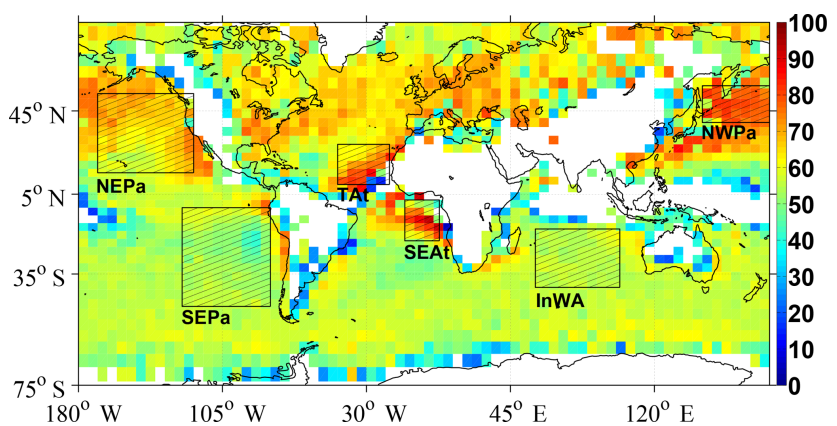

Figure 6. Six regions of high AAC occurrence, further defined in Table 5. Background map is the global annual $4^{\circ} \times 5^{\circ}$ nighttime AAC occurrence frequency ( $f_{\mathrm{AAC}}$; see Eq. (3) and Fig. 2 for seasonal $f_{\text {AAC }}$ maps). Global annual maximum, median and mean $f_{\text {AAC }}$ values are respectively $93 \%, 57 \%$ and $57 \%$.

\subsubsection{Regional results of DARE $O W C$}

The $f_{\text {AAC }}$ results in Fig. 2 help us define six major AAC "hotspots" over the northeast Pacific (NEPa), southeast Pacific (SEPa), tropical Atlantic (TAt), southeast Atlantic (SEAt), Indian ocean, offshore from western Australia (InWA) and northwest Pacific (NWPa). To assist in the analysis of the remaining figures in this study, Figure 6 and Table 5 briefly describe these six AAC hotspots.

Figure 7a illustrates the mean regional, seasonal or annual estimates of SW TOA DARE $\mathrm{OWC}_{\mathrm{O}}\left(\mathrm{W} \mathrm{m}^{-2}\right)$ in each region of Table 5. Figure 7b-f show the primary parameters used

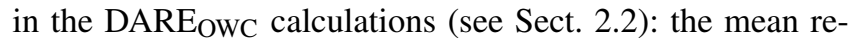
gional, seasonal or annual (panel b) percentage of grid cells that show valid (i.e., positive) $f_{\mathrm{AAC}} \times \tau_{\mathrm{AAC}}^{\mathrm{DR}}$ values compared to the total number of $4^{\circ} \times 5^{\circ}$ pixels in each region; (panel c) CALIOP $f_{\text {AAC }}$ values; (panel d) CALIOP $f_{\text {AAC }} \times \tau_{\mathrm{AAC}}^{\mathrm{DR}}$ values; (panel e) assumed overlying SSA values at $546.3 \mathrm{~nm}$; and (panel f) assumed underlying COD values from MODIS.

Table 6 reports the estimated seasonal or annual regional minimum, maximum, mean and standard deviations of our

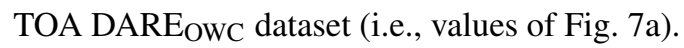

(a) SW TOA DARE OWC $\left(\mathrm{W} \mathrm{m}^{-2}\right)$

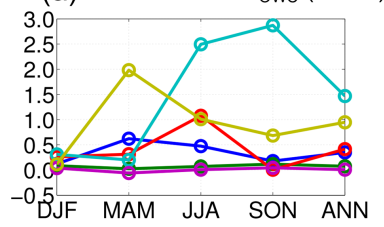

(b) Valid grid cells in region (\%)

(c) CALIOP $\mathrm{f}_{\mathrm{AAC}}(\%)$

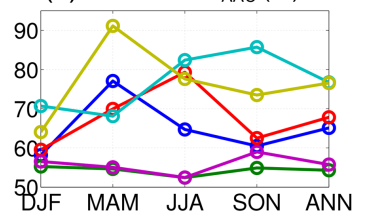

(e) Auxiliary SSA (n. u.)

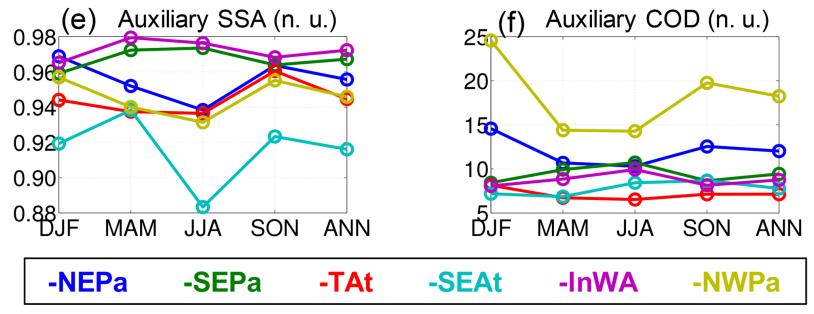

Figure 7. Mean regional, seasonal or annual (a) estimated SW TOA DARE $_{\text {OWC }}\left(\mathrm{W} \mathrm{m}^{-2}\right.$, calculation is described in Sect. 2.2), (b) percentage of grid cells that show valid $f_{\mathrm{AAC}} \times \tau_{\mathrm{AAC}}^{\mathrm{DR}}$ (i.e., positive) values compared to the total number of $4^{\circ} \times 5^{\circ}$ pixels in each region, (c) CALIOP $f_{\mathrm{AAC}}(\%)$, (d) $f_{\mathrm{AAC}} \times \tau_{\mathrm{AAC}}^{\mathrm{DR}}$ (no unit), (e) assumed overlying SSA at $546.3 \mathrm{~nm}$ from a combination of MODIS-OMICALIOP and (f) assumed underlying COD from MODIS in each region of Table 5. DARE $\mathrm{OWC}_{\mathrm{C}}$ in (a) is computed using the Case IV of Table 4.

We record positive TOA DARE OWC values above $1 \mathrm{~W} \mathrm{~m}^{-2}$ in Fig. 7a over TAt in JJA $(1.08 \pm 1.66)$, SEAt in JJA and SON $(2.49 \pm 2.54$ and $2.87 \pm 2.33)$, and NWPa in MAM $(1.98 \pm 1.85)$. Let us note that the highest positive

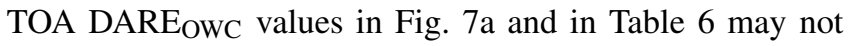
be entirely representative of each region, because they are based on a smaller number of valid DARE OWC $_{\text {results }}(86 \%$ valid values in JJA in TAt, 58\%-88 \% in JJA-SON in SEAt and $69 \%$ in MAM in NWPa). SEAt and NWPa are the only 
Table 5. Six regions of high AAC occurrence (see Fig. 6), their season of highest AAC occurrence and its corresponding mean $f_{\mathrm{AAC}}$ value.

\begin{tabular}{lll}
\hline Region & [latitude; longitude] & Season of most $f_{\text {AAC }}$ \\
\hline Northeast Pacific Ocean (NEPa) & $16^{\circ} \mathrm{N}$ to $52^{\circ} \mathrm{N}, 170^{\circ} \mathrm{W}$ to $120^{\circ} \mathrm{W}$ & $\mathrm{MAM}(80 \%)$ \\
Southeast Pacific Ocean (SEPa) & $49^{\circ} \mathrm{S}$ to $2^{\circ} \mathrm{S}, 126^{\circ} \mathrm{W}$ to $80^{\circ} \mathrm{W}$ & $\mathrm{DJF}(55 \%)$ \\
Tropical Atlantic Ocean (TAt) & $10^{\circ} \mathrm{N}$ to $30^{\circ} \mathrm{N}, 45^{\circ} \mathrm{W}$ to $18^{\circ} \mathrm{W}$ & $\mathrm{JJA}(80 \%)$ \\
Southeast Atlantic Ocean (SEAt) & $19^{\circ} \mathrm{S}$ to $2^{\circ} \mathrm{N}, 10^{\circ} \mathrm{W}$ to $8^{\circ} \mathrm{E}$ & $\mathrm{SON}(87 \%)$ \\
Indian Ocean, offshore from western Australia (InWA) & $41^{\circ} \mathrm{S}$ to $13^{\circ} \mathrm{S}, 58^{\circ} \mathrm{E}$ to $102^{\circ} \mathrm{E}$ & $\mathrm{SON}(60 \%)$ \\
Northwest Pacific Ocean (NWPa) & $40^{\circ} \mathrm{N}$ to $55^{\circ} \mathrm{N}, 145^{\circ} \mathrm{E}$ to $180^{\circ} \mathrm{E}$ & $\mathrm{MAM}(90 \%)$ \\
\hline
\end{tabular}

Table 6. Estimated SW TOA DARE $\mathrm{OWC}\left(\mathrm{W} \mathrm{m}^{-2}\right.$, setting is Case IV of Table 4) in each region of Table 5.

\begin{tabular}{lrrrrrr}
\hline Region & Min, max & mean DJF & mean MAM & mean JJA & mean SON & mean ANN \\
\hline NEPa & $-0.57,5.10$ & $0.12 \pm 0.18$ & $0.62 \pm 0.79$ & $0.47 \pm 0.78$ & $0.18 \pm 0.25$ & $0.35 \pm 0.50$ \\
SEPa & $-0.21,2.85$ & $0.09 \pm 0.19$ & $0.02 \pm 0.15$ & $0.07 \pm 0.37$ & $0.12 \pm 0.44$ & $0.07 \pm 0.29$ \\
TAt & $-1.02,5.25$ & $0.26 \pm 0.43$ & $0.31 \pm 0.43$ & $1.08 \pm 1.66$ & $0.01 \pm 0.42$ & $0.41 \pm 0.74$ \\
SEAt & $0.20,7.59$ & $0.31 \pm 1.09$ & $0.20 \pm 0.41$ & $2.49 \pm 2.54$ & $2.87 \pm 2.33$ & $1.47 \pm 1.59$ \\
InWA & $-0.39,0.83$ & $0.04 \pm 0.16$ & $-0.06 \pm 0.10$ & $0.01 \pm 0.11$ & $0.04 \pm 0.27$ & $0.01 \pm 0.16$ \\
NWPa & $0.07,5.72$ & $0.11 \pm 0.14$ & $1.98 \pm 1.85$ & $1.01 \pm 1.65$ & $0.68 \pm 0.46$ & $0.95 \pm 1.02$ \\
\hline
\end{tabular}

regions showing an all-positive range of DARE $\mathrm{OWC}_{\text {values }}$ in Table 6 (i.e., within 0.20 and 7.59 and within 0.07 and $5.72 \mathrm{~W} \mathrm{~m}^{-2}$ respectively). The spread (i.e., standard deviation) of those mean regional DARE OwC $_{\text {is }}$ of the same order of magnitude as the mean values themselves. For example, although TAt shows an annual mean DARE OwC value of $0.41 \mathrm{~W} \mathrm{~m}^{-2}$, most points (i.e., about $68 \%$, assuming a normal distribution of DARE OWC) are within $0.41 \pm 0.74 \mathrm{~W} \mathrm{~m}^{-2}$ (see Table 6). Those regions and seasons of highly positive DARE $_{\text {OWC }}$ values are associated with the highest CALIOP $\tau_{\mathrm{AAC}}^{\mathrm{DR}} \times f_{\mathrm{AAC}}$ values (see Fig. 7d: 0.12 in JJA in TAt, $0.12-$ 0.13 in JJA-SON in SEAt and 0.10 in MAM in NWPa). They are also associated with lower SSA values (i.e., $<0.94$ in Fig. 7e), typical of more light-absorbing aerosols such as biomass burning. The underlying COD values are fairly constant (between $\sim 5$ and 10 in Fig. 7f), except for a noticeably higher COD over the NWPa region (between $\sim 15$ and 25 in Fig. 7f). NWPa is the region of highest latitudes in our study (i.e., between 40 and $55^{\circ} \mathrm{N}$ ). More variation in the COD at higher latitudes is also observed in Fig. A2 in the Appendix. This agrees with King et al. (2013), who show a larger zonal variation of COD (and increased uncertainty in the MODIS cloud property retrievals) in the higher latitudes of both hemispheres, particularly in winter (see their Fig. 12b).

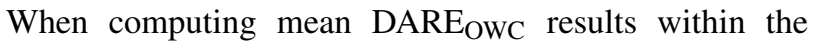
"southeast Atlantic" region defined in Zhang et al. (2016) (i.e., $30^{\circ} \mathrm{S}$ to $10^{\circ} \mathrm{N} ; 20^{\circ} \mathrm{W}$ to $20^{\circ} \mathrm{E}$ instead of $19^{\circ} \mathrm{S}$ to $2^{\circ} \mathrm{N}$; $10^{\circ} \mathrm{W}$ to $8^{\circ} \mathrm{E}$ in our study), we find a small fraction of valid pixels (i.e., an average of $\sim 37 \%$ ) but a mean annual DARE $_{\text {OWC }}$ value of $0.57 \mathrm{~W} \mathrm{~m}^{-2}$, which resides within their

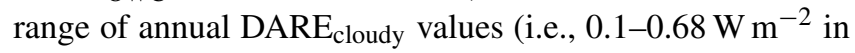
Zhang et al., 2016). Similar to Matus et al. (2015), the sea- son of highest DARE $E_{\text {OWC }}$ is $\mathrm{SON}$ over the southeast Atlantic

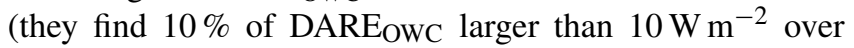
thick clouds with COD $>1$; see their Fig. 9d). However, our DARE $_{\text {OwC }}$ results are significantly higher than the ones in Zhang et al. (2016) in our SEAt region (defined as a smaller region and offshore from the "southeast Atlantic" region in Zhang et al., 2016) as well as in the TAt (similar latitudelongitude boundaries to the ones of region "TNE Atlantic" in Zhang et al., 2016) and the NWPa (similar boundaries to "NW Pacific" in Zhang et al., 2016) regions.

We emphasize that the DARE OWC $_{\text {estimates in this study }}$ are not directly comparable to many previous studies (see Table 1) because of different spatial domain, period, satellite sensors and associated uncertainties. This will lead to the detection of different fractions of AAC above different types of clouds and different AAC types across the globe. The calculations of DARE $\mathrm{E}_{\text {cloudy }}$ can also differ greatly depending on different AAC aerosol radiative properties assumptions above clouds (especially absorption) and different assumptions in aerosol and cloud vertical heights (see Table 1).

Apart from the major differences in methods and sensors, it seems reasonable to say that we are missing AAC cases over pure dust-dominant regions such as the Arabian Sea or the TAt region (compared to Zhang et al., 2016, and Matus et al., 2015, for example). Both Matus et al. (2015) and Zhang et al. (2016) use the CALIOP Level 2 standard products to distinguish among a few aerosol types and infer specific aerosol optical properties in their DARE cloudy $_{\text {. Accord- }}$ ing to Fig. 1d, SEAt, TAt and the Arabian Sea are regions where we might be missing up to $40 \%$ of AAC cases when using the DR technique compared to the CALIOP standard products. The number of potentially missing AAC cases in our study is larger over the Arabian sea $\left(0-30^{\circ} \mathrm{N}\right.$ and $40-$ 
$80^{\circ} \mathrm{E}$ due to the limited number of OWCs suitable for the DR method (see Appendix B1). Zhang et al. (2016) show that pure dust aerosols over these dust-dominant regions tend to produce a negative $\mathrm{DARE}_{\text {cloudy }}$ when the underlying COD is below $\sim 7$ and this is the case for most of the clouds over these regions in their study. In summary, two factors in the DR method seem to hamper the detection of AAC in these regions: the low cloud optical depths of underlying clouds and very few cases of "clear air" above clouds. As a consequence, we propose that the positive DARE OwC $_{\text {values in our study }}$ should, in reality, be counter-balanced by more negative dust-

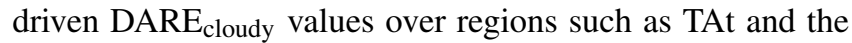
Arabian Sea. On the other hand, the DARE $\mathrm{D}_{\text {cloudy }}$ results from Matus et al. (2015) and Zhang et al. (2016) might also differ from the true global DARE $E_{\text {cloudy }}$ state of the planet for different reasons. As described in Matus et al. (2015), using CALIOP Level 2 standard products as in Matus et al. (2015) and Zhang et al. (2016) could lead to possible misclassification of dust aerosols as clouds (Omar et al., 2009), specifically around cloud edges in the TAt region. Moreover, even if the AAC is correctly detected in Matus et al. (2015) and Zhang et al. (2016), the amount of AAC AOD might be biased low due to their use of the CALIOP Level 2 standard products (Kacenelenbogen et al., 2014).

\section{Uncertainties in our DARE above-cloud results and the path forward}

\subsection{Detecting and quantifying the true amount of $\mathrm{AAC}$ cases}

Our study mainly uses CALIOP Level 1 measurements to detect aerosols above specific OWCs that satisfy the criteria given in Table B2. We suggest that the number of CALIOP profiles that contain aerosols over any type of cloud (instead of only OWCs in this study) should be informed by a combination of different techniques applied to CALIOP observations (e.g., the standard products, the DR and the CR technique). Airborne observations such as those from the $\mathrm{Ob}-$ seRvations of Aerosols above Clouds and their intEractionS (ORACLES) field campaigns (Zuidema et al., 2016) are well suited for providing further guidance on when to apply which technique.

To the best of our knowledge, the true global occurrence of aerosols above any type of cloud remains unknown. This question cannot be entirely answered with the use of CALIOP observations only. We suggest that a more complete global quantification and characterization of aerosol above any type of cloud should be informed by a combination of AAC retrievals from CALIOP, passive satellite sensors (e.g., POLDER (Waquet et al., 2013a, b; Peers et al., 2015; Deaconu et al., 2017), MODIS (Meyer et al., 2013; Zhang et al., 2014, 2016; see Table 2) and model simulations (Schulz et al., 2006).

\subsection{Considering the diurnal variability of aerosol and cloud properties}

While we consider the diurnal cycle of solar zenith angles

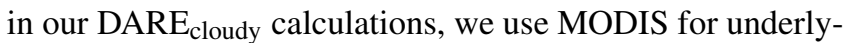
ing COD and cloud $R_{\mathrm{e}}$ information as well as a combination of MODIS, OMI and CALIOP for overlying aerosol properties (see Sect. 2.2). By using A-Train satellite observations (i.e., the AQUA, AURA and CALIPSO platforms), with an overpass time of 13:30 local time at the Equator, we are only using a daily snapshot of cloud and aerosol properties and not considering their daily variability.

Min and Zhang (2014) show a strong diurnal cycle of cloud fraction over the SEAt region (i.e., a 5-year mean trend of diurnal cloud fraction using SEVIRI that varies from $\sim 60 \%$ in the late afternoon to $80 \%$ in the early morning on their Fig. 4). According to Min and Zhang (2014) (see their Table 2), assuming a constant cloud fraction derived from MODIS/AQUA generally leads to an underestimation (less positive) by $\sim 16 \%$ in the DARE all-sky $_{\text {calculations (see }}$ Eq. 1). Further studies should explore the implications of diurnal variations of COD and cloud $R_{\mathrm{e}}$ on DARE $\mathrm{E}_{\text {cloudy }}$ results using, for example, geostationary observations from SEVIRI.

Daily variations of aerosol (intensive and extensive) radiative properties above clouds cannot be ignored either. Arola et al. (2013) and Kassaniov et al. (2013) both show that even when the AOD varies strongly during the day, the accurate prediction of $24 \mathrm{~h}$ average $\mathrm{DARE}_{\text {non-cloudy }}$ requires only daily averaged properties. However, in the case of under-sampled aerosol properties, such as when using ATrain derived aerosol properties (this study), the error in the $24 \mathrm{~h}$ DARE $E_{\text {non-cloudy }}$ can be as large as $100 \%$ (Kassaniov et al., 2013). Xu et al. (2016) show that the daily mean TOA DARE $_{\text {non-cloudy }}$ is overestimated by up to $3.9 \mathrm{~W} \mathrm{~m}^{-2}$ in the summertime in Beijing if they use a constant MODIS AQUA AOD value, compared to accounting for the observed hourlyaveraged daily variability. Kassaniov et al. (2013) propose that using a simple combination of MODIS TERRA and AQUA products would offer a reasonable assessment of the daily averaged aerosol properties for an improved estimation of $24 \mathrm{~h}$ DARE $\mathrm{non}_{\text {-cloudy }}$.

\subsection{Considering the spatial and temporal variability of cloud and aerosol fields}

We have used coarse-resolution (i.e., $4^{\circ} \times 5^{\circ}$ ) seasonally gridded aerosol and cloud properties in our DARE OwC $_{\text {calcula- }}$ tions (see Sect. 2.2). As a consequence, subgrid-scale variability (or heterogeneity) of cloud and aerosol properties has not been considered. This approach is similar to assuming spatially and temporally homogeneous cloud and aerosol fields in our DARE $\mathrm{OWC}_{\mathrm{W}}$ results.

Marine boundary layer (MBL) clouds show significant small-scale horizontal variability (Di Girolamo et al., 2010; Zhang et al., 2011). Using mean gridded COD in DARE $E_{\text {cloudy }}$ 
calculations, for example, can lead to significant biases in DARE $_{\text {cloudy }}$ calculations, an effect called the "plane-parallel albedo bias" (e.g., Oreopoulos et al., 2007; Di Girolamo et al., 2010; Zhang et al., 2011, 2012). Min and Zhang (2014) show that using a mean gridded COD significantly overestimates (by $\sim 10 \%$ over the SEAt region) the DARE cloudy $_{\text {. }}$ results when the cloud has significant subgrid horizontal heterogeneity. Furthermore, this overestimation increases with increasing AOD, COD and cloud inhomogeneity. Future studies should examine the difference between DARE $E_{\text {cloudy }}$ results calculated with gridded mean COD and cloud $R_{\mathrm{e}}$ values (this study) and DARE $E_{\text {cloudy }}$ results calculated with MODIS Level 3 joint histograms of MODIS COD and cloud $R_{\mathrm{e}}$ (e.g., similar to Min and Zhang, 2014).

Aerosol spatial variation can be significant over relatively short distances of 10 to $100 \mathrm{~km}$, depending on the type of environment (Anderson et al., 2003; Kovacs, 2006; Santese et al., 2007; Shinozuka and Redemann, 2011; Schutgens et al., 2013). Shinozuka and Redemann (2011) argue that only a few environments can be more heterogeneous than the Canadian phase of the ARCTAS (Arctic Research of the Composition of the Troposphere from Aircraft and Satellites) experiment, where the air mass was subject to fresh local biomass emissions. In this type of environment, they observed a $19 \%$ variability of the AOD over a $20 \mathrm{~km}$ length (comparable in scale to a $\sim 0.1^{\circ} \times 0.1^{\circ}$ area). They also found a $2 \%$ variability in the AOD over the same length in a contrasting homogeneous environment that occurred after a long-range aerosol transport event. As a consequence, similar to using a mean gridded underlying COD and cloud $R_{\mathrm{e}}$, using mean gridded overlying aerosol radiative properties could very well bias our DARE ${ }_{\text {OWC }}$ results.

As a preliminary investigation into the sources and magnitudes of these potential biases, we have used TOA DARE $_{\text {non-cloudy }}$ (see Eq. 1) estimates derived using wellcollocated aerosol properties (hereafter called "retrieve-thenaverage" or R-A) from a companion study (Redemann et al., 2019; see Appendix A) and compared those to DARE $_{\text {non-cloudy }}$ estimates computed using seasonally gridded mean aerosol properties at seasonally gridded mean vertical heights (hereafter called "average-then-retrieve" or A$\mathrm{R})$. Both DARE $E_{\text {non-cloudy }}$ results obtained with the two methods are compared over ocean and at a resolution of $4^{\circ} \times 5^{\circ}$.

A majority (i.e., $\sim 58 \%$ ) of A-R DARE non-cloudy $_{\text {results }}$ are within $\pm 35 \%$ of the R-A DARE $E_{\text {non-cloudy }}$ results. We find very few (i.e., $\sim 1 \%$ ) negative R-A DARE $E_{\text {non-cloudy values }}$

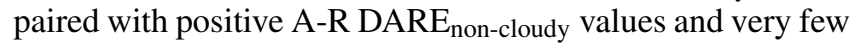
large differences between both methods (i.e., less than $1 \%$ of the differences are above $\pm 10 \mathrm{~W} \mathrm{~m}^{-2}$ ). However, we find a

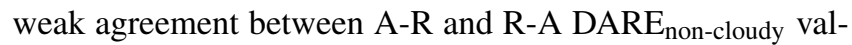
ues during each of the seasons (i.e., a correlation coefficient between 0.21 and 0.34 ). The A-R DARE $E_{\text {non-cloudy values are }}$ generally biased high relative to the R-A calculations, as illustrated by positive mean and median values of the A-R to R-A differences $\left(0.64\right.$ and $0.92 \mathrm{~W} \mathrm{~m}^{-2}$ respectively; stan- dard deviation of 2.25). When computing the global sea-

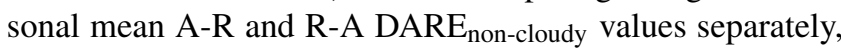
we find that the global seasonal A-R DARE $E_{\text {non-cloudy values }}$ overestimate the global seasonal R-A DARE non-cloudy values by $17 \%, 19 \%, 21 \%$ and $17 \%$ in DJF, MAM, JJA and SON. Moreover, the seasonal median A-R DARE non-cloudy values

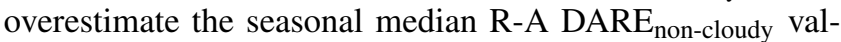
ues in all six regions of Table 5 (i.e., median differences between $0.28 \mathrm{~W} \mathrm{~m}^{-2}$ in NWPa in SON and $3.05 \mathrm{~W} \mathrm{~m}^{-2}$ in SEAt in JJA). The geospatial distributions of these differences in DARE calculation strategies are illustrated in Fig. 8.

\subsection{Assuming similar intensive aerosol properties above clouds and in nearby cloud-free skies}

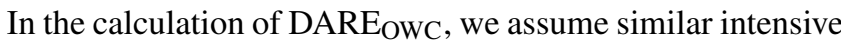
aerosol properties above clouds and in nearby clear skies. This assumption might not be valid and should be investigated in future studies by comparing aerosol properties and their probability distributions over clear and cloudy conditions using observations from the ORACLES field campaign.

\subsection{Assuming fixed aerosol and cloud vertical layers}

Finally, longwave (LW) radiative forcing is particularly dependent on the vertical distribution of aerosols, especially for light-absorbing aerosols (Chin et al., 2009). This is because the energy these aerosols reradiate depends on the temperature, and hence their altitude. For example, Penner et al. (2003) emphasize the importance of soot and smoke aerosol injection height in LW TOA DARE all-sky $_{\text {(see Eq. 1) }}$ simulations (higher injection heights tend to enhance the negative $\mathrm{LW}$ radiative forcing).

Quijano et al. (2000), Chung et al. (2005) and Chin et al. (2009) demonstrate the importance of an aerosol height, in relation to a cloud height (i.e., the aerosols located above, within or below the clouds) in an accurate estimation of SW

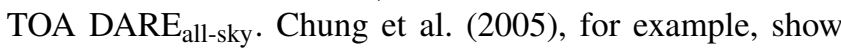
that varying the relative vertical distribution of aerosols and clouds leads to a range of global anthropogenic SW TOA DARE $_{\text {all-sky }}$ from -0.1 to $-0.6 \mathrm{~W} \mathrm{~m}^{-2}$ (using a combination of MODIS satellite, AERONET ground-based observations and CTM simulations; see their Table 2).

However, here, we concentrate on cases of aerosol layers overlying clouds in order to compute $\mathrm{SW}$ TOA DARE $\mathrm{E}_{\text {cloudy }}$. Aerosol and cloud layer heights are assumed constant across the globe in our study (see Sect. 2.2). Future studies should incorporate mean gridded (i.e., $4^{\circ} \times 5^{\circ}$ in this study) seasonal CALIOP Level 2 aerosol and cloud vertical profiles into the calculation of DARE OWC.

However, constraining clouds between 2 and $3 \mathrm{~km}$ in our study does not seem unreasonable as our AAC AOD calculations using the DR method can only be applied to aerosols overlying specific low opaque water clouds with, among other criteria, an altitude below $3 \mathrm{~km}$ (see Table B2). On the 

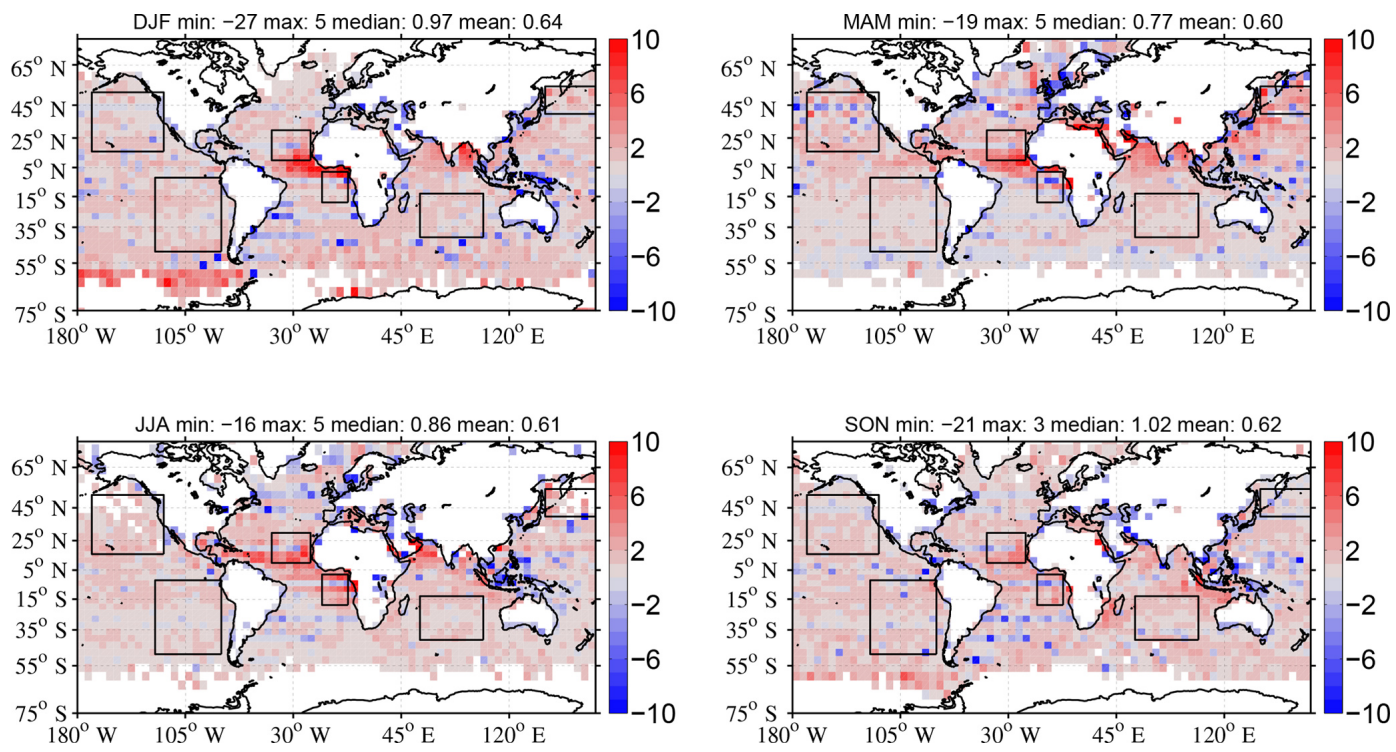

Figure 8. Seasonal maps showing the differences in SW TOA DARE $E_{\text {non-cloudy }}$ computed using the average-then-retrieve (A-R) and the retrieve-then-average (R-A) strategies. Positive values (in red) show regions where the A-R DARE calculations are larger, whereas negative values (in blue) show regions where the R-A DARE calculations are larger. The squares show different regions defined in Table 5. The title of each map shows the global minimum, maximum, median and mean values.

other hand, constraining aerosols between 3 and $4 \mathrm{~km}$ in our study is not realistic over many parts of the globe (e.g., see Fig. 7 of Devasthale et al., 2011). For example, over the region of the southeast Atlantic during the ORACLES campaign, the HSRL team observed an aerosol layer located on average between 2 and $5 \mathrm{~km}$, and overlying a cloud at an average altitude of $1.2 \mathrm{~km}$.

According to Zarzycki et al. (2010), the underlying cloud properties are orders of magnitude more crucial to the computation of DARE cloudy $_{\text {than }}$ the location of the aerosol layer relative to the cloud, as long as the aerosol is above the cloud. In other words, the forcing does not seem to depend on the height of the aerosols above clouds as much as other parameters such as the AOD, SSA or cloud albedo. Zarzycki et al. (2010) investigated this assumption and found that over low and middle clouds, forcing changed by $\sim 1 \%-3 \%$ through the heights where the Black Carbon burden was the largest. These small changes in forcing are likely products of a change in atmospheric transmission above the aerosol layer (Haywood and Ramaswamy, 1998) (e.g., a change in the aerosol height is linked to a change in the integrated column water vapor above the aerosol layer and this, in turn, would alter the incident solar radiation).

\section{Conclusions}

We have computed a first approximation of global seasonal TOA shortwave direct aerosol radiative effects (DARE) above opaque water clouds (OWCs), DARE OWC, $_{\text {, using }}$ observation-based aerosol and cloud radiative properties from a combination of A-Train satellite sensors and a radiative transfer model. Our DARE OWC $_{\text {calculations make }}$ three major departures from previous peer-reviewed results: (1) they use extensive aerosol properties derived from the depolarization ratio (DR) method applied to Level 1 CALIOP measurements, whereas previous studies often use CALIOP Level 2 standard products which introduce higher uncertainties and known biases; (2) our DARE OwC $_{\text {calculations are }}$ applied globally, while most previous studies focus on specific regions of high AAC occurrence such as the southeast Atlantic; and (3) our calculations use intensive aerosol properties retrieved from a combination of A-Train satellite sensor measurements (e.g., MODIS, OMI and CALIOP).

Our study agrees with previous findings on the locations and seasons of the maximum occurrence of AAC across the globe. We identify six regions of high AAC occurrence (i.e., AAC hotspots): South and North East Pacific (SEAt and $\mathrm{NEPa}$ ), tropical and southeast Atlantic (TAt and SEAt), Indian Ocean offshore from western Australia (InWA), and northwest Pacific (NWPa). We define $\tau_{\mathrm{AAC}}^{\mathrm{DR}}$, the aerosol optical depth (AOD) above OWCs, using the DR method on CALIOP measurements, $f_{\mathrm{AAC}}$, and the frequency of occurrence of AAC cases. We record a majority of $\tau_{\mathrm{AAC}}^{\mathrm{DR}} \times f_{\mathrm{AAC}}$ values at $532 \mathrm{~nm}$ in the $0.01-0.02$ range and that can exceed 0.2 over a few AAC hotspots.

We find positive averages of global seasonal DARE $\mathrm{OWC}_{\mathrm{WC}}$ between 0.13 and $0.26 \mathrm{~W} \mathrm{~m}^{-2}$ and an annual global mean DARE $_{\text {OWC }}$ value of $0.20 \mathrm{~W} \mathrm{~m}^{-2}$ (i.e., a warming effect on climate). Regional seasonal DARE $\mathrm{OWC}_{\mathrm{W}}$ values range from $-0.06 \mathrm{~W} \mathrm{~m}^{-2}$ in the Indian Ocean, offshore from west- 
ern Australia (in March-April-May), to $2.87 \mathrm{~W} \mathrm{~m}^{-2}$ in the southeast Atlantic (in September-October-November). High positive values are usually paired with high aerosol optical depths $(>0.1)$ and low single scattering albedos $(<0.94)$, representative of biomass burning aerosols, for example.

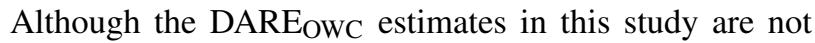
directly comparable to previous studies because of different spatial domains, periods, satellite sensors, detection methods and/or associated uncertainties, we emphasize that they are notably higher than the ones from Zhang et al. (2016), Matus et al. (2015) and Oikawa et al. (2013). In addition to differences in satellite sensors, AAC detection methods and the assumptions enforced in the calculation of DARE $\mathrm{Dloudy}_{\text {, there }}$ are several other factors that may contribute to the overall

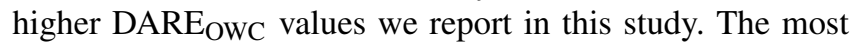
likely contributors are (1) a possible underestimate of the number of dust-dominated AAC cases; (2) our use of the DR method on CALIOP Level 1 data to quantify the AAC AOD; and, in particular, (3) the technique we have chosen for aggregating subgrid aerosol and cloud spatial and temporal variability. We discuss each of these in turn in the following paragraphs.

Two factors seem to be preventing the DR method from recording enough AAC cases in these regions: the low cloud optical depths of underlying clouds and very few cases of "clear air" above clouds. The DR method used in this study is restricted to aerosols above OWCs that satisfy a long list of criteria. The AAC dataset in this study underestimates (i) the total number of CALIOP $5 \mathrm{~km}$ profiles that contain AAC over all OWCs (i.e., not just suitable to the DR technique), (ii) the total number of CALIOP $5 \mathrm{~km}$ profiles that contain AAC over any type of clouds across the globe and (iii) the true global occurrence of AAC over any type of clouds. To the best of our knowledge, the true amount of AAC in (i), (ii) and (iii) remains unknown. A better characterization of the "unobstructed" OWCs in the application of the DR technique on CALIOP measurements might bring us closer to answering (i). A combination of CALIOP standard, DR and CR techniques together with airborne observations (e.g., from the ORACLES field campaign) might answer (ii). Finally, (iii) cannot be answered with only the use of CALIOP observations. The results in this study should be combined with aerosol-above-cloud retrievals from passive satellite sensors (e.g., POLDER, Waquet et al., 2013a, b; Peers et al., 2015; Deaconu et al., 2017, or MODIS, Meyer et al., 2013; Zhang et al., 2014, 2016) and model simulations (Schulz et al., 2006) to obtain a more complete global quantification and characterization of aerosol above any type of clouds.

Compared to other methods, the DR technique applied to CALIOP measurements retrieves $\tau_{\mathrm{AAC}}^{\mathrm{DR}}$ with fewer assumptions and lower uncertainties. Other global DARE $E_{\text {cloudy }}$ results (e.g., Matus et al., 2015, and Zhang et al., 2016) use CALIOP standard products to detect the AAC cases, quantify the AAC AOD and define the aerosol type (and specify the aerosol intensive properties). These studies rely on the presence of aerosol in concentrations sufficient to be identified by the CALIOP layer detection scheme, and on the ability of the CALIOP aerosol subtyping algorithm to correctly identify the aerosol type and thus select the correct lidar ratio for the AOD retrieval. While several recent studies have taken various approaches to quantifying the amount of aerosol that is not currently being detected in the CALIOP backscatter signals, their general conclusions are unanimous. The CALIOP standard products underestimate above-cloud aerosol loading and the corresponding AAC AOD (Kacenelenbogen et al., 2014; Kim et al., 2017; Toth et al., 2018; Watson-Parris et al., 2018), and this in turn leads to underestimates of both DARE $E_{\text {non-cloudy }}$ and DARE cloudy $_{\text {(Thorsen }}$ and $\mathrm{Fu}, 2015$; Thorsen et al., 2017).

In this study, we have assumed spatially and temporally homogeneous clouds and aerosols in our DAREOWC calculations. As a preliminary investigation of such effects on our calculations, we have compared DARE calculations derived from well collocated aerosol properties (retrieve-thenaverage) to DARE calculations using seasonally gridded mean aerosol properties (average-then-retrieve). We have shown that the average-then-compute DARE results generally overestimate the retrieve-then-average results both on a global scale and in each of our selected regions. Further research and analysis are required to determine which of these two computational approaches provides the most accurate estimates of real-world DARE.

Data availability. This study used the following ATrain data products: (i) CALIPSO version 3 lidar level 1 profile products (Powell et al., 2013; NASA Langley Research Center Atmospheric Science Data Center; https://doi.org/10.5067/CALIOP/CALIPSO/CAL_LID_L1ValStage1-V3-01_L1B-003.01; last access: 26 September 2018), (ii) CALIPSO version 3 lidar level $25 \mathrm{~km}$ cloud layer products (Powell et al., 2013; NASA Langley Research Center Atmospheric Science Data Center; https://doi.org/10.5067/CALIOP/CALIPSO/CAL_LID_L2_05km CLay-Prov-V3-01_L2-003.01; last access: 26 September 2018), (iii) MODIS Atmosphere L2 Version 6 Aerosol Product (Levy and Hsu, 2015; NASA MODIS Adaptive Processing System, Goddard Space Flight Center, USA; https://doi.org/10.5067/MODIS/MOD04_L2.006; last access: 26 September 2018), and (iv) L2 Version 3 OMI products OMAERO (Stein-Zweers and Veefkind, 2012) and OMAERUV (Torres, 2006). 
Appendix A: Method to obtain aerosol radiative properties in non-cloudy (i.e., clear-sky) conditions using MODIS, OMI and CALIOP and to estimate

DARE $_{\text {non-cloudy }}$

A companion paper, Redemann et al. (2019), develops and refines a method for retrieving full spectral (i.e., at 30 different wavelengths) extinction coefficients, single scattering albedo (SSA) and asymmetry parameters from satellite aerosol products in non-cloudy (i.e., clear-sky) conditions. The method requires collocation of quality-screened satellite data, selection of aerosol models that reproduce the satellite observations within stated uncertainties and forward calculation of aerosol radiative properties based on the selected aerosol models. They use MODIS-Aqua AOD at 550 and $1240 \mathrm{~nm}$, CALIPSO integrated backscattering (IBS) at $532 \mathrm{~nm}$ and OMI absorption aerosol optical depth (AAOD) at $388 \mathrm{~nm}$ (see Table A1). The aerosol radiative properties resulting from this method are called MOC retrievals (for MODIS-OMI-CALIOP).

The choice of OMI satellite algorithms (see Table A1) reflects their assessment of the representativeness of subsampling OMI data along the CALIPSO track; i.e., they compared the probability distribution function (PDF) of the OMI retrievals along the CALIPSO track to the global PDF and chose the dataset that had the best match between global and along-track PDF for the over-ocean and two over-land datasets, the latter being different in their use of MODIS Dark Target (DT) versus Enhanced Deep Blue (EDB) data as the source of AOD. They collocate the MODIS and OMI products within a $40 \mathrm{~km} \times 40 \mathrm{~km}$ box centered at each CALIPSO $5 \mathrm{~km}$ profile location after Redemann et al. (2012). For the OMAERUV dataset, they choose the SSA product for the layer height indicated by the collocated CALIOP backscatter profile.
Their aerosol models emulate those of the MODIS aerosol over-ocean algorithm (Remer et al., 2005). Like the MODIS algorithm, they define each model with a lognormal size distribution and wavelength-dependent refractive index. They then combine two of these models, weighted by their number concentration, and compute optical properties for the bimodal lognormal size distribution. Unlike the MODIS algorithm, they allow combinations of two fine-mode or two coarse-mode models. They use 10 different aerosol models, which stem from some of the MODIS over-ocean models (Remer et al., 2005) but include more absorbing models, which was motivated by application of their methodology to the Arctic Research of the Composition of the Troposphere from Aircraft and Satellites (ARCTAS) field campaign data, requiring more aerosol absorption than included in the current MODIS over-ocean aerosol models. They use MOC spectral aerosol radiative properties to then calculate direct aerosol radiative effects (i.e., DARE $\mathrm{n}_{\text {non-cloudy }}$; see Eq. 1) through a delta-four stream radiative transfer model with 15 spectral bands from 0.175 to $4.0 \mu \mathrm{m}$ in $\mathrm{SW}$ and 12 longwave (LW) spectral bands between 2850 and $0 \mathrm{~cm}^{-1}(\mathrm{Fu}$ and Liou, 1992).

In order to use these MOC parameters (retrieved in clearskies) in our DARE $\mathrm{OWC}_{\mathrm{W}}$ calculations, we need to assume similar aerosol intensive properties in clear skies compared to above clouds and we need to spatially and/ or temporally grid these MOC parameters. As discussed in Sect. 2.2, we use seasonally averaged MOC spectral SSA, aerosol asymmetry parameter and extinction retrievals on $4^{\circ} \times 5^{\circ}$ grids. Figure A1 illustrates seasonal maps of MOC SSA used in our calculations of DARE $\mathrm{OWC}$.

The DARE $\mathrm{OWC}_{\mathrm{W}}$ calculations in our study also require information about the underlying cloud optical properties. As discussed in Sect. 2.2, we use seasonally mean gridded COD from MODIS such as illustrated in Fig. A2.

Table A1. Datasets currently used for global MODIS-OMI-CALIOP (MOC) retrievals of aerosol radiative properties (Redemann et al., 2019); DT: Dark Target; EDB: Enhanced Deep Blue.

\begin{tabular}{lllr}
\hline Product & Source & Assumed uncertainties $^{1}$ & Weight $^{1,2}$ \\
\hline $550 \mathrm{~nm}$ AOD & MODIS Collection 6 (ocean, DT-land, EDB-land) & $\pm 5 \% \pm 30 \mathrm{M} \mathrm{m}^{-1}$ & 0.1488 \\
$1240 \mathrm{~nm}$ AOD & MODIS Collection 6 (extrapolated spectrally over land) & $\pm 5 \% \pm 30 \mathrm{M} \mathrm{m}^{-1}$ & 0.1422 \\
$388 \mathrm{~nm}$ AAOD & OMI (OMAERO for ocean, OMAERUV for DT-land), MODIS EDB & $\pm 30 \% \pm 50 \mathrm{M} \mathrm{m}^{-1}$ & 0.5542 \\
$532 \mathrm{~nm}$ IBS & CALIPSO V3-01 & $\pm 30 \% \pm 0.1 \mathrm{M} \mathrm{m}^{-1} \mathrm{sr}^{-1}$ & 0.1548 \\
\hline
\end{tabular}

${ }^{1}$ For the values after division by CALIPSO layer depth. ${ }^{2}$ The weight, $w_{i}$, is used to calculate the cost function $X=\left(\Sigma w_{i}\left(\left(x_{i}-\hat{x}_{i}\right) / \delta \hat{x}_{i}\right)^{2}\right)^{1 / 2}$, where $x_{i}$ denotes the retrieved parameters, $\hat{x}_{i}$ denotes the observables, and $\delta \hat{x}_{i}$ denotes the uncertainties in the observables. 

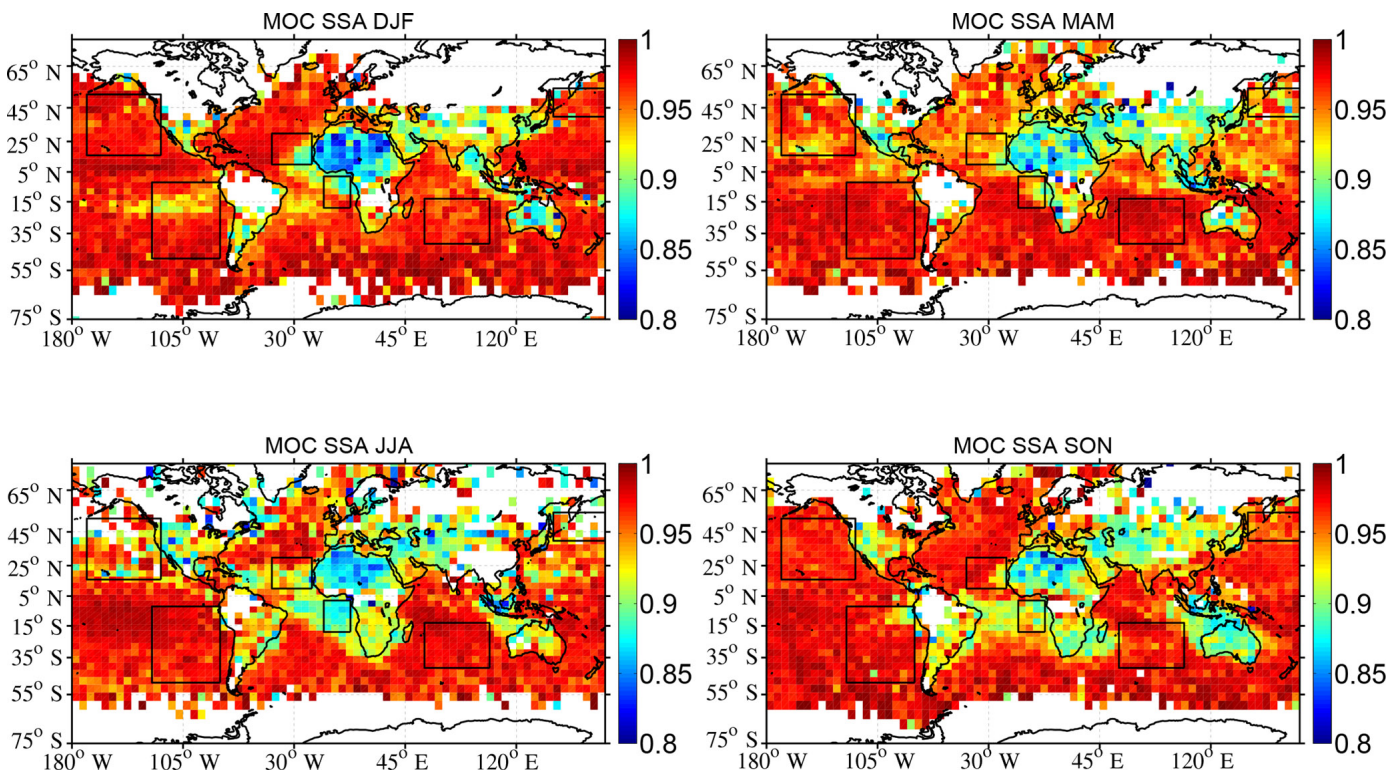

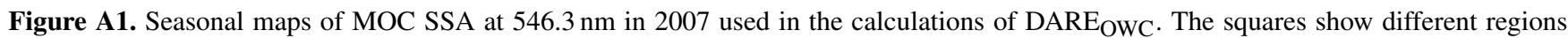
defined in Table 5.
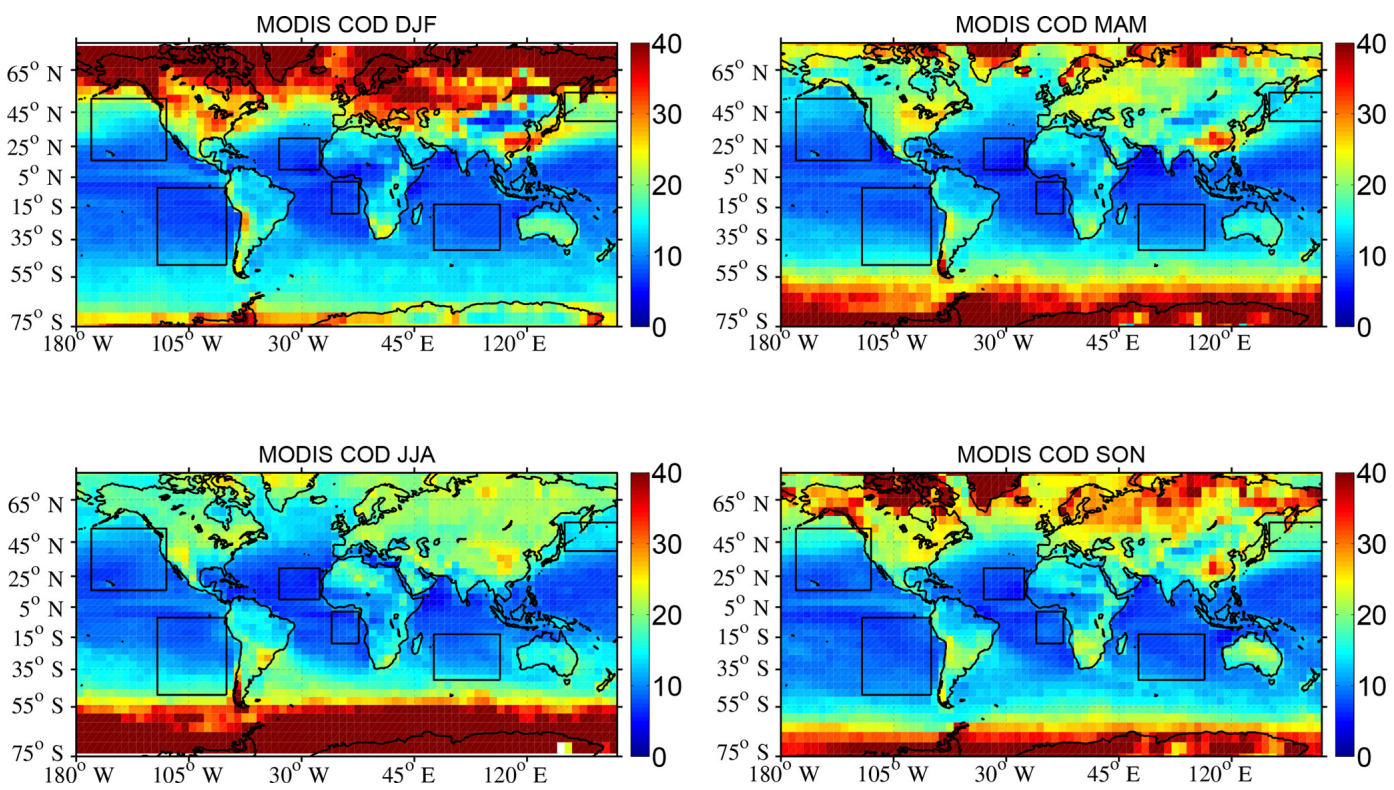

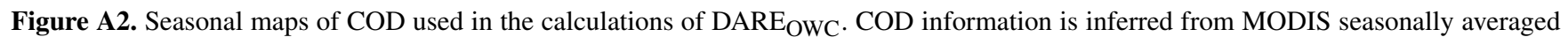
monthly $1^{\circ} \times 1^{\circ}$ grids (i.e., liquid water cloud products of MYD08_M3: "Cloud Effective Radius Liquid Mean Mean" and "Cloud Optical Thickness Liquid Mean Mean"; Platnick et al., 2015) from 2008 to 2012. The squares show different regions defined in Table 5. 
Table B1. Steps required to compute $\tau_{\mathrm{AAC}}^{\mathrm{DR}}$.

\begin{tabular}{|c|c|c|c|}
\hline Step & Description & CALIOP, GEOS-5 and other computed products that are used in each step & More detail \\
\hline S1 & $\begin{array}{l}\text { Select specific Opaque Water } \\
\text { Clouds (OWC) suitable for the DR } \\
\text { technique }\end{array}$ & $\begin{array}{l}\text { CAD Score }^{2} \text {, Integrated Attenuated Backscatter Uncertainty } 532^{2} \text {, Inte- } \\
\text { grated Volume Depolarization Ratio Uncertainty }{ }^{2} \text {, Horizontal Averaging, } \\
\text { Opacity Flag }^{2}, \text { Feature Classification Flags }^{2}, \text { Layer Top Altitude }^{2}, \text { Layer } \\
\text { Top Temperature }^{2} \text {, Surface Wind Speed }\end{array}$ & $\begin{array}{l}\text { Appendix B1, } \\
\text { Table B2 }\end{array}$ \\
\hline S2 & $\begin{array}{l}\text { Select a subset of OWCs from (S1) } \\
\text { with clear air above }\end{array}$ & $\begin{array}{l}\text { Overlying Integrated Attenuated Backscatter } 532^{2} \text {, simulated molecular } \\
\text { layer-integrated attenuated backscatter (Powell et al., 2002, 2006) and } \\
\text { OWCs from (S1) }\end{array}$ & Appendix B2 \\
\hline S3 & $\begin{array}{l}\text { Process seasonal maps of median } \\
\mathrm{IAB}_{\text {SS,CAC }}^{\text {OWC }} \text { and record number of } \\
\mathrm{IAB}_{\text {SS,CAC }}^{\text {OWC }} \text { values per grid cell }\end{array}$ & $\begin{array}{l}\text { Integrated Attenuated Backscatter } 532^{2} \text {, Integrated Volume Depolariza- } \\
\text { tion Ratio }{ }^{2} \text {, and OWCs with clear air above from (S2) }\end{array}$ & Appendix B3 \\
\hline S4 & Compute $\tau_{\mathrm{AAC}}^{\mathrm{DR}}$ along track & $\begin{array}{l}\text { Total Attenuated Backscatter } 532^{1} \text {, Molecular Number Density }{ }^{1} \text {, Ozone } \\
\text { Number Density }{ }^{1} \text { Integrated Attenuated Backscatter } 532^{2,+}, \\
\text { Integrated Volume Depolarization Ratio } \\
\text { Base Altitude }{ }^{2,+} \text { and season Top Altitude }{ }^{2,+} \text {, Layer } \\
\text { Note: }{ }^{(+)} \text {these parameters are re-computed from CALIOP level } 1 \text { data, } \\
\text { and may differ from the standard CALIOP products }\end{array}$ & $\begin{array}{l}\text { Eq. (2) or } \\
\text { (B1) }\end{array}$ \\
\hline S5 & $\begin{array}{l}\text { Process seasonal maps of median } \\
\tau_{\mathrm{AAC}}^{\mathrm{DR}} \text { and record number of } \tau_{\mathrm{AAC}}^{\mathrm{DR}} \\
\text { values per grid cell }\end{array}$ & $\begin{array}{l}\tau_{\mathrm{AAC}}^{\mathrm{DR}} \text { of (S4) and we filter using number of } \mathrm{IAB}_{\mathrm{SS}, \mathrm{CAC}}^{\mathrm{OWC}} \text { values per grid } \\
\text { cell and per season from }(\mathrm{S} 3)\end{array}$ & $\begin{array}{l}\text { Results in } \\
\text { Sect. } 3.2\end{array}$ \\
\hline
\end{tabular}

* We construct global maps of $4 \times 5^{\circ}$ pixels using median values. Superscripts 1 and 2 denote respectively CALIOP Level 1 and Level 2 aerosol or cloud layer products.

\section{Appendix B: Method for AAC detection and AAC AOD computation}

The depolarization ratio (DR) method (Hu et al., 2007b) used to derive estimates of the optical depths $(\tau)$ of aerosols above clouds (AAC) is given in Eq. (2) and repeated here for convenience:

$\tau_{\mathrm{AAC}}^{\mathrm{DR}}=-0.5 \times \ln \left[\mathrm{IAB}_{\mathrm{SS}, \mathrm{AAC}}^{\mathrm{OWC}} / \mathrm{IAB}_{\mathrm{SS}, \mathrm{CAC}}^{\mathrm{OWC}}\right]$.

The subscripts SS and CAC represent, respectively, "single scattering" and "clear above clouds". IAB OWC (i.e., either $\mathrm{IAB}_{\mathrm{SS}, \mathrm{AAC}}^{\mathrm{OWC}}$ or $\mathrm{IAB}_{\mathrm{SS}, \mathrm{CAC}}^{\mathrm{OWC}}$ ) is the single scattering integrated attenuated backscatter (IAB), derived from the product of the measured $532 \mathrm{~nm}$ attenuated backscatter coefficients integrated from cloud top to cloud base, $\mathrm{IAB}^{\mathrm{OWC}}$, and a layer effective multiple scattering factor, $\eta^{\mathrm{OWC}}$, derived from the layer-integrated volume depolarization ratio of the water cloud (called $\delta^{\mathrm{OWC}}$ ) using the following:

$\eta^{\mathrm{OWC}}=\left[\left(1-\delta^{\mathrm{OWC}}\right) /\left(1+\delta^{\mathrm{OWC}}\right)\right]^{2}$

(Hu et al., 2007a). The single scattering IAB is thus derived using the following:
$\mathrm{IAB}_{\mathrm{SS}, X}^{\mathrm{OWC}}=\eta^{\mathrm{OWC}} \times \mathrm{IAB}_{\text {measured }, X}^{\mathrm{OWC}}$

for both aerosol above cloud cases ( $X=\mathrm{AAC})$ and those cases with clear skies above $(X=\mathrm{CAC})$. An assumption of the DR method is that $\delta^{\mathrm{OWC}}$ is negligibly affected by any aerosols that lie in the optical path between the OWC and the lidar.

Table B1 provides a high-level overview of the procedure we use to compute aerosol optical depth $\left(\tau_{\mathrm{AAC}}^{\mathrm{DR}}\right)$ above OWCs across the globe. We chose to concentrate on nighttime CALIOP observations only, as they have substantially higher signal-to-noise ratios (SNRs) than the daytime measurements (Hunt et al., 2009).

The first step (S1) is to identify OWCs that are suitable for the application of the DR method. The acceptance criteria used to identify these clouds are described below in Appendix B1 and listed in Table B2. In the second step (S2), we use the overlying integrated attenuated backscatter (i.e., the $532 \mathrm{~nm}$ attenuated backscatter coefficients integrated from TOA to the OWC cloud tops) to partition the OWC into two classes: (i) "unobstructed" clouds, for which the magnitude of the overlying IAB suggests that only aerosol-free clear skies lie above and (ii) "obstructed" clouds for which we expect to be able to retrieve positive estimates of $\tau_{\mathrm{AAC}}^{\mathrm{DR}}$. Sec- 
tion B2 describes the objective method we have developed to separate unobstructed clouds (for which we can compute $\mathrm{IAB}_{\mathrm{SS}, \mathrm{CAC}}^{\mathrm{OWC}}$ ) from obstructed clouds (for which we calculate $\mathrm{IAB}_{\mathrm{SS}, \mathrm{AAC}}^{\mathrm{OWC}}$ ).

In step (S3), we construct global seasonal maps of median IAB SS,CAC $_{\text {OWC }}$ using 5 consecutive years (2008-2012) of CALIOP nighttime data (see Appendix B3). By doing this we can subsequently compute estimates of $\tau_{\mathrm{AAC}}^{\mathrm{DR}}$ without invoking assumptions about the lidar ratios of water clouds in clear skies (Hu et al., 2007). Throughout this study, we chose to compute global median values within each grid cell (instead of mean values) to limit the impact of particularly high or low outliers on our statistics.

In step (S4), we compute estimates of $\tau_{\mathrm{AAC}}^{\mathrm{DR}}$ for all obstructed OWC within each grid cell using Eq. (2) or (B1) and the 5-year nighttime seasonal median values of $\mathrm{IAB}_{\mathrm{SS}, \mathrm{CAC}}^{\mathrm{OWC}}$ from (S3) (i.e., each $\tau_{\mathrm{AAC}}^{\mathrm{DR}}$ value along the CALIOP track is computed using one median value of $\mathrm{IAB}_{\mathrm{SS}, \mathrm{CAC}}^{\mathrm{OWC}}$ per $4^{\circ} \times 5^{\circ}$ pixel and per season).

For the OWCs considered in this study, true layer base cannot be measured by CALIOP, simply because the signal becomes totally attenuated at some point below the layer top. Instead, what is reported in the CALIOP data products is an apparent base, which indicates the point at which the signal was essentially indistinguishable from background levels. Numerous validation studies have established the accuracy of the CALIOP cloud layer detection scheme (e.g., McGill et al., 2007; Kim et al., 2011; Thorsen et al., 2011; Yorks et al., 2011; Candlish et al., 2013). Strong attenuation of the signal by optically thick aerosols above an OWC can, in some cases, introduce biases into the cloud height determination, which would lead to misestimating IAB $\mathrm{SSC}_{\mathrm{SS}, \mathrm{AAC}}$ and subsequent errors in $\tau_{\mathrm{AAC}}^{\mathrm{DR}}$. To ensure the use of consistent data processing assumptions throughout our retrievals of $\tau_{\mathrm{AAC}}^{\mathrm{DR}}$, we recalculated the components of $\mathrm{IAB}_{\mathrm{SS} \text {.AAC }}^{\mathrm{OWC}}$ (i.e., the "Integrated Attenuated Backscatter 532" and "Integrated Volume Depolarization Ratio") using parameters in the CALIOP Level 1 product ("Total Attenuated Backscatter 532", "Molecular Number Density" and "Ozone Number_Density") and optimized estimates of cloud top and base altitudes based on the "Layer Top Altitude" and "Layer Base Altitude" values reported in the CALIOP Level 2 layer product.

Apart from the identification of specific OWCs in step (S1), the primary Level 2 CALIOP parameters used to calculate $\tau_{\mathrm{AAC}}^{\mathrm{DR}}(\mathrm{S} 2-\mathrm{S} 4$ in Table B1) are (i) the integrated attenuated backscatter above cloud top to detect "clear air" cases (i.e., "Overlying Integrated Attenuated Backscatter 532" in step S2), (ii) the layer integrated attenuated backscatter of the OWC with clear air above (i.e., "Integrated Attenuated Backscatter 532" in step S3) and (iii) the cloud multiple scattering factor, derived as a function of the layer integrated volume depolarization ratio (i.e., the "Integrated Volume Depolarization Ratio" in S3 and S4).
Below, we list the potential sources of errors associated with those three products:

a. the accuracy of the $532 \mathrm{~nm}$ channel calibrations,

b. the SNR of the backscatter data within the layer,

c. the estimation of molecular scattering in the integrated attenuated backscatter (Sect. 3.2.9.1 of the CALIPSO Feature Detection ATBD, http://www-calipso.larc.nasa. gov/resources/pdfs/PC-SCI-202_Part2_rev1x01.pdf, last access: 27 September 2005) and

d. the accuracy of the depolarization calibration (see Sect. 5 in Powell et al., 2009).

Concerning (a), Rogers et al. (2011) show that the NASA LaRC HSRL and CALIOP Version $3532 \mathrm{~nm}$ total attenuated backscatter agree on average within $\sim 3 \%$, demonstrating the accuracy of the CALIOP $532 \mathrm{~nm}$ calibration algorithms.

Concerning (b), we assume the influence of the SNR returned from the OWC is negligible as the OWCs are strongly scattering features and our dataset is composed of nighttime data only. However, the backscatter from tenuous and spatially diffuse aerosol layers with large extinctionto-backscatter ratios can lie well beneath the CALIOP attenuated backscatter detection threshold. When such layers lie above OWCs, the measured overlying integrated attenuated backscatter can fall within 1 standard deviation of the expected "purely molecular" value that is used to identify CAC (or "unobstructed") OWC in our dataset (S2; see Appendix B2). Within the context of this study, these tenuous and spatially diffuse aerosol layers can have appreciable $\mathrm{AOD}$, and thus care must be taken to ensure that these sorts of cases are not misclassified as CAC OWC. Appendix B3 discusses such cases, possibly found, for example, over the region of SEAt.

\section{B1 Select specific opaque water clouds suitable for DR technique}

Successful application of the DR method (Eq. 2 or B1) requires a very specific type of underlying cloud (step S1 in Table B1). Table B2 lists the criteria we have applied to the CALIOP $5 \mathrm{~km}$ cloud layer products for the selection of these specific OWCs across the globe.

We ensure that each cloud is the only cloud detected within the vertical column $(\mathrm{C} 1)$ and is guaranteed to be of high quality by imposing filters on various CALIOP quality assurance flags (C2). Imposing the "single-shot cloud cleared fraction $=0$ " in criterion (C3) ensures that the clouds are uniformly detected at single-shot resolution throughout the full $5 \mathrm{~km}$ (15 shot) horizontal extent. As a result, we will intentionally miss any broken clouds and any clouds that show a weaker scattering intensity within one or more laser pulses with the 15 shot average. On the other hand, enforcing the single-shot cloud fraction $=0$ criteria simultaneously 
Table B2. Criteria used to select the opaque water clouds (OWCs) for the application of the DR method to obtain the AAC frequency of occurrence, AAC optical depth, AAC lidar ratio and DARE $\mathrm{OWC}_{\mathrm{C}}$ in this study.

\begin{tabular}{lll}
\hline Criteria & Metric & Interpretation \\
\hline $\mathrm{C} 1$ & Number of cloud layers $=1$ & a single cloud in each column \\
\hline $\mathrm{C} 2$ & $\begin{array}{l}\text { High CALIOP cloud-aerosol discrimination }(\mathrm{CAD}) \text { score }(90 \leq \mathrm{CAD} \leq 100) \\
\left.\text { and high SNR (IAB SNR }>159, \delta^{\mathrm{OWC}} \mathrm{SNR}>2\right)\end{array}$ & $\begin{array}{l}\text { highly confident of cloud clas- } \\
\text { sification }\end{array}$ \\
\hline $\mathrm{C} 3$ & $\begin{array}{l}\text { Cloud detected at } 5 \mathrm{~km} \text { averaging resolution with CALIOP single-shot cloud } \\
\text { cleared fraction }=0\end{array}$ & $\begin{array}{l}\text { cloud is spatially uniform over } \\
\text { a } 5 \mathrm{~km} \text { averaging interval }\end{array}$ \\
\hline $\mathrm{C} 4$ & CALIOP opacity flag $=1 ;$ surface wind speed $<9 \mathrm{~m} \mathrm{~s}^{-1}$ & cloud is opaque \\
\hline $\mathrm{C} 5$ & $\begin{array}{l}\text { CALIOP phase classification is high-confidence water; } \delta^{\mathrm{OWC}}<0.5 ; \text { cloud top } \\
\text { altitude }<3 \mathrm{~km} \text {; cloud top temperature } \geq-10^{\circ} \mathrm{C}\end{array}$ & $\begin{array}{l}\text { highly confident of cloud phase } \\
\text { identification (water) }\end{array}$ \\
\hline
\end{tabular}

ensures that all $\tau_{\mathrm{AAC}}^{\mathrm{DR}}$ values in this study will lie below a certain threshold: larger values would attenuate the signal to the point that single-shot detection of underlying clouds is no longer likely. Consequently, some highly attenuating biomass burning events (e.g., with $\tau_{\mathrm{AAC}}^{\mathrm{DR}}>2.5$ ) can be excluded from the cases considered here.

At high surface wind speeds over oceans, the CALIOP V3 layer detection algorithm may fail to detect surface backscatter signals underneath optically thick but not opaque layers. In such cases, CALIOP's standard algorithm may misclassify the column as containing an opaque overlying cloud. To avoid such scenarios, we exclude all the cases with high surface wind conditions (C4). Let us note that this condition was applied on the entire dataset, disregarding the surface type (i.e., land or ocean), as our OWC dataset resides mostly over ocean surfaces (see Fig. 1b).

Criterion (C5) requires that the OWC be both low enough (cloud top below $3 \mathrm{~km}$ ) and warm enough (cloud top temperature above $-10^{\circ} \mathrm{C}$ as in Zelinka et al., 2012) to ensure that it is composed of liquid water droplets. After applying all the criteria of Table B2, the median OWC top height of our dataset is $\sim 1.6 \mathrm{~km}$. According to $\mathrm{Hu}$ et al. (2009), any feature showing a cloud layer integrated volume depolarization ratio above $50 \%$ should correspond to an ice cloud with randomly oriented particles. Criterion (C5) ensures the deletion of such cases.

The averaged single-layer, high-QA (quality assurance), uniform cloud (i.e., C1-C3 in Table B2) has a top altitude of $\sim 8 \mathrm{~km}$, a top temperature around $-38^{\circ} \mathrm{C}$ and mean surface winds of $\sim 6 \mathrm{~m} \mathrm{~s}^{-1}$. Selecting only those clouds with top temperatures above $-10{ }^{\circ} \mathrm{C}$ removes $30 \%-40 \%$ of the observations. Subsequently filtering out clouds with top heights above $3 \mathrm{~km}$ removes an additional $30 \%$ of the observations. Finally, filtering out clouds with underlying winds above $9 \mathrm{~m} \mathrm{~s}^{-1}$ deletes another $20 \%$ of the observations. Among all single-layer, high-QA, uniform clouds (i.e., C1-C3 in Table B2), we find that $\sim 45 \%-50 \%$ are opaque clouds (C4), and that $\sim 11 \%-12 \%$ satisfy all criteria $(\mathrm{C} 1-\mathrm{C} 5)$ of Table B2.

\section{B2 Select a subset of opaque water clouds with clear air above}

To distinguish between OWCs with clear skies above (i.e., unobstructed clouds; see S2 in Table B1) and those with overlying aerosols, we examine the overlying integrated attenuated backscatter reported in the CALIOP Level 2 cloud layer products. The total IAB value above a cloud (i.e., $\mathrm{IAB}_{\text {aboveCloud }}^{\text {tot }}$ ) can be written as follows:

$$
\begin{aligned}
\mathrm{IAB}_{\text {aboveCloud }}^{\text {tot }} & =\int_{0}^{\text {cloudtop }}\left[\beta_{\mathrm{a}}(r) T_{\mathrm{a}}^{2}(0, r) T_{\mathrm{m}}^{2}(0, r)\right] \mathrm{d} r \\
& +\int_{0}^{\text {cloudtop }}\left[\beta_{\mathrm{m}}(r) T_{\mathrm{m}}^{2}(0, r) T_{\mathrm{a}}^{2}(0, r)\right] \mathrm{d} r .
\end{aligned}
$$

Here $\beta_{\mathrm{a}}(r)$ and $\beta_{\mathrm{m}}(r)$ are, respectively, the aerosol and the molecular backscatter coefficients $\left(\mathrm{km}^{-1} \mathrm{sr}^{-1}\right)$ at range $r(\mathrm{~km})$, and $T_{\mathrm{a}}^{2}(0, r)$ and $T_{\mathrm{m}}^{2}(0, r)$ are the two-way transmittances between the lidar (at range $r=0$ ) and range $r$ due to, respectively, aerosols and molecules.

Figure B1 shows simulated profiles of the integrated attenuated backscatter above any given altitude, $z,\left(\mathrm{IAB}_{\text {above } z}^{\mathrm{mol}}\right)$ for a purely molecular atmosphere for both daytime (solid green curve) and nighttime conditions (dashed green curve). These data were generated by the CALIPSO lidar simulator (Powell et al., 2002, 2006; Powell, 2005) using molecular and ozone number density profiles obtained from the GEOS-5 atmospheric data products distributed by the NASA Goddard Global Modeling and Assimilation Office (GMAO). The error envelopes at \pm 1 standard deviation (light blue curves) and \pm 1.5 standard deviation (dark blue curves) around the mean represent measurement uncertainties for CALIPSO profiles averaged to a nominal horizontal distance of $5 \mathrm{~km}$. The mean $\mathrm{IAB}_{\text {above } z}^{\mathrm{mol}}$ profiles represent an average of all data 


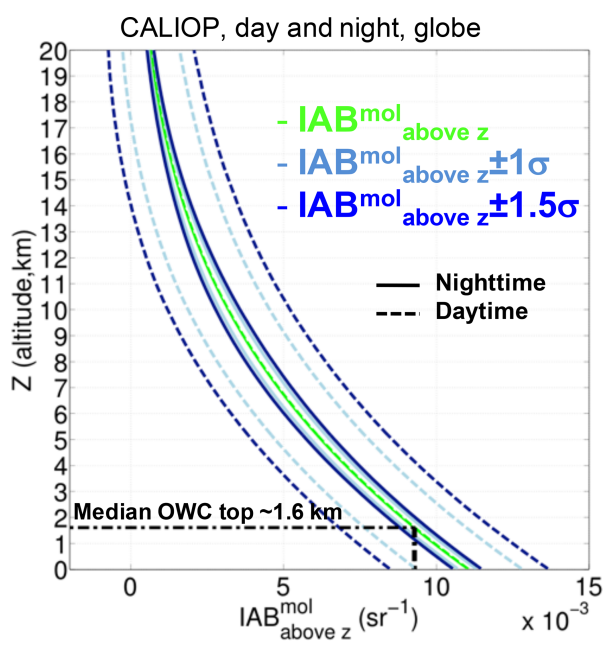

Figure B1. Nighttime (solid) and daytime (dashed) simulated vertical profile of integrated attenuated backscatter above any given altitude, $z, \mathrm{IAB}_{\text {above } z}^{\mathrm{mol}}$ (green curve). The light blue (respectively dark blue) envelope shows 1 (respectively 1.5) standard deviation $(\sigma)$ around the $\mathrm{IAB}_{\text {above } z}^{\mathrm{mol}}$ profile. Data were generated by the CALIPSO lidar simulator (Powell et al., 2002, 2006). The $\mathrm{IAB}_{\text {above } z}^{\mathrm{mol}}$ value associated with the median OWC top height of $\sim 1.6 \mathrm{~km}$ in our dataset corresponds to $0.0093 \mathrm{sr}^{-1}$.

along the CALIPSO orbit track on 17 March 2013 that began at 03:29:28 UTC and extended from $78.8^{\circ} \mathrm{N}, 20.3^{\circ} \mathrm{E}$ to $77.3^{\circ} \mathrm{S}, 77.0^{\circ} \mathrm{W}$. Spot checks of mean $\mathrm{IAB}_{\text {above } z}^{\mathrm{mol}}$ profiles from different seasons show variations of $\sim 10 \%$ or less, depending on latitude, for altitudes of $3 \mathrm{~km}$ and below. The largest differences are found poleward of $30^{\circ}$. While the daytime and nighttime mean values are, as expected, essentially indistinguishable from one another, the error envelopes differ drastically due to the influence of solar background noise during daylight measurements. In this study, we use nighttime measurements only.

In this study, we assume "clear air" when $\mathrm{IAB}_{\text {aboveCloud }}^{\text {tot }}$ is within the simulated $\mathrm{IAB}_{\mathrm{aboveCloud}}^{\mathrm{mol}}$ value $\pm 1 \sigma$ (i.e., the light blue envelope shown in Fig. B1). This definition of "clear air above" conditions is somewhat more restrictive than those imposed in previous studies. For example, Liu et al. (2015) conducted an extensive study of AAC optical depths and lidar ratios using CALIOP measurements over the tropical and southeast Atlantic. To identify clear air above cloud cases, Liu et al. (2015) require that the integrated attenuated scattering ratio, defined as

$$
\mathrm{ASR}=\frac{\int_{8 \mathrm{~km}}^{\mathrm{OWC}_{\mathrm{top}}}\left(\beta_{\mathrm{m}}(r)+\beta_{\mathrm{a}}(r)\right) T_{\mathrm{m}}^{2}(0, r) T_{\mathrm{a}}^{2}(0, r) \mathrm{d} r}{\int_{8 \mathrm{~km}}^{\mathrm{OWC}} \beta_{\mathrm{m}}(r) T_{\mathrm{m}}^{2}(0, r) \mathrm{d} r},
$$

fall within the range of $0.95<\mathrm{ASR}<1.05$, irrespective of cloud top altitude. For comparison, at the maximum OWC top altitude used in our analyses $(3 \mathrm{~km}),\left(\mathrm{IAB}_{\text {aboveCloud }}^{\mathrm{mol}} \pm\right.$ $1 \sigma) / \mathrm{IAB}_{\text {aboveCloud }}^{\mathrm{mol}}=1 \pm 0.0380$. This restriction tightens for lower cloud top heights; e.g., at our mean OWC top altitude of $1.6 \mathrm{~km},\left(\mathrm{IAB}_{\text {aboveCloud }}^{\mathrm{mol}} \pm 1 \sigma\right) / \mathrm{IAB}_{\text {aboveCloud }}^{\mathrm{mol}}=1 \pm 0.0325$.

The pioneering study by Chand et al. (2008), who first used the CALIOP DR method to assess the radiative effects of aerosols above clouds, took a different approach to identifying "clear above cloud" cases. Rather than examining the overlying IAB, they instead assumed clear air above conditions whenever $\mathrm{IAB}_{\mathrm{SS}}^{\mathrm{OWC}}>0.025 \mathrm{sr}^{-1}$. As will be shown in Appendix B3, in addition to the $\mathrm{IAB}_{\text {aboveCloud }}^{\mathrm{mol}}$ limits cited above, our study also enforces limits on IAB $\mathrm{SSC}_{\mathrm{SSC}}$. This combination of limits on both $\mathrm{IAB}_{\text {aboveCloud }}^{\mathrm{mol}}$ and $\mathrm{IAB}_{\mathrm{SS}, \mathrm{CAC}}^{\mathrm{OWC}}$ serves to more effectively reject aerosol-contaminated profiles from the "clear above" dataset than either one alone.

\section{B3 Process median seasonal maps of integrated attenuated backscatter of opaque water clouds showing clear air above}

Once we select specific OWCs (i.e., that satisfy the criteria of Table B2) and define which ones are "unobstructed" (see Appendix B2), we can easily compute $\mathrm{IAB}_{\mathrm{SS}, \mathrm{CAC}}^{\mathrm{OWC}}$ by using Eq. (B3). For clouds that totally attenuate the lidar signal (i.e., cloud optical depths greater than $\sim 6$; Young et al., 2018), $\mathrm{IAB}_{\text {SS.CAC }}^{\text {OWC }}$ in Eq. (2) or (B1) is related to the OWC lidar ratio (called $S_{\mathrm{c}}$ ), so that

$$
S_{\mathrm{c}}=1 /\left(2 \times \eta^{\mathrm{OWC}} \times \mathrm{IAB}_{\mathrm{CAC}}^{\mathrm{OWC}}\right)=1 /\left(2 \times \mathrm{IAB}_{\mathrm{SS}, \mathrm{CAC}}^{\mathrm{OWC}}\right)
$$

(Platt, 1973). OWC $S_{\mathrm{c}}$ values are relatively stable at the visible and near-infrared wavelengths (Pinnick et al., 1983; O'Connor et al., 2004) but show large variations over land (Pinnick et al., 1983; Hu et al., 2006). $S_{\mathrm{c}}$ is known to vary as a function of cloud droplet microphysics, and is especially sensitive to cloud droplet effective radius $\left(R_{\mathrm{e}}\right)$ and the imaginary part of the refractive index (see Fig. 8 of Deaconu et al., 2017). Hu et al. (2006), Liu et al. (2015) and Deaconu et al. (2017) show that a decrease in $R_{\mathrm{e}}$ is often paired with an increase in estimated $S_{\mathrm{c}}$ at $532 \mathrm{~nm}$ for pure, non-aerosolcontaminated water clouds (i.e., cloud droplets having an imaginary refractive index of 0 ).

As an example, Fig. B2a shows the median nighttime CALIOP $S_{\mathrm{c}}$ values across the globe during 2008. Figure B2b shows MODIS AQUA-derived mean liquid water $R_{\mathrm{e}}$ in 2008 (using MODIS Level 3 monthly product "Cloud Effective Radius Liquid Mean Mean").

Greater $S_{\mathrm{c}}$ values paired with lower cloud $R_{\mathrm{e}}$ can be seen offshore and close to the west coasts of Africa and the Americas in Fig. B2. Other notable regions of low cloud $R_{\mathrm{e}}$ and high $S_{\mathrm{c}}$ in Figure B2 are above industrial regions like northern Europe, the eastern US and Southeast Asia. These results appear to support Twomey's analysis (Twomey, 1977; Rosenfeld and Lensky, 1998), showing an enhancement of the cloud albedo through the increase in droplet number concentration and a decrease in the droplet size driven by in- 

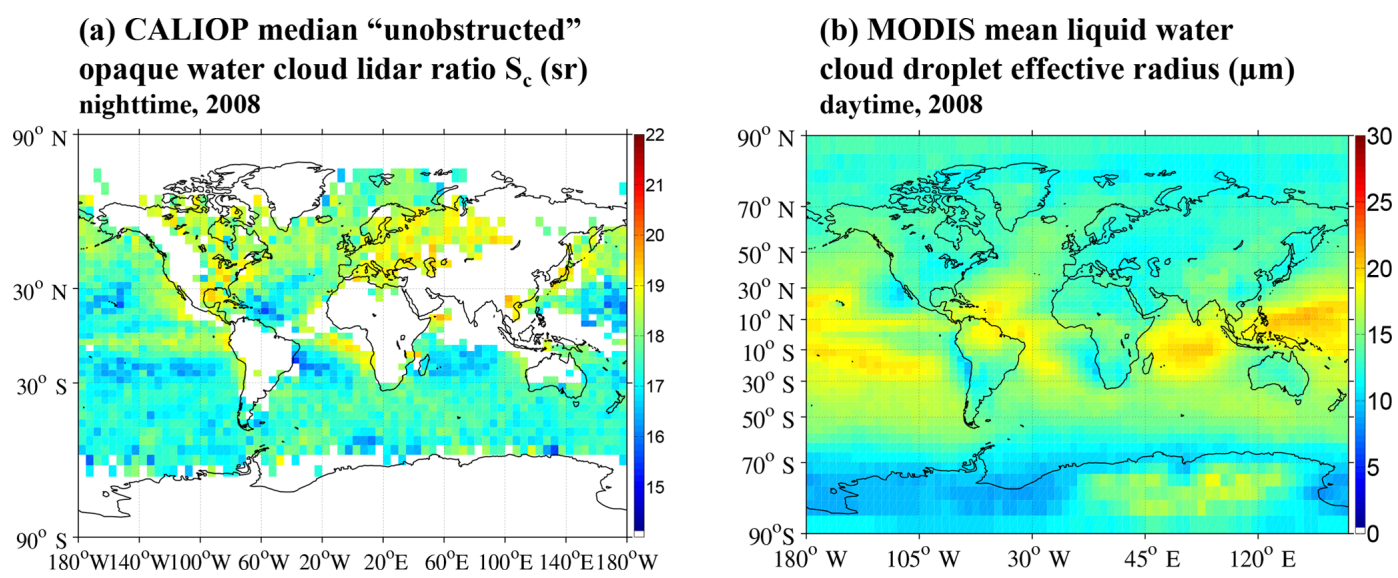

Figure B2. (a) Global CALIOP yearly median nighttime "unobstructed" (i.e., clear air above) OWC lidar ratio, $S_{\mathrm{c}}$, in 2008 that satisfies all criteria of Table B2. For the reasons outlined in this section, any OWC along the CALIOP track for which $S_{\mathrm{c}}>20 \mathrm{sr}$ or $S_{\mathrm{c}}<14 \mathrm{sr}$ is deleted before temporal and spatial averaging. White pixels show a limited number of OWCs; (b) Global MODIS yearly mean daytime liquid water cloud droplet effective radius, $R_{\mathrm{e}}$ (in $\mu \mathrm{m}$, “Cloud Effective Radius Liquid Mean Mean” parameter from MODIS MYD08_M3 product).

creased aerosol concentration. On the other hand, Fig. B2a mostly exhibits low $S_{\mathrm{c}}$ values (paired with large $R_{\mathrm{e}}$ ) over the inter-tropical convergence zone (ITCZ), likely associated with deep convective regimes. In addition, Fig. B2a generally shows larger OWC $S_{\mathrm{c}}$ values in the Northern Hemisphere than in the Southern Hemisphere, which we attribute to differences in sources of cloud condensation nuclei. Figure B2b shows patterns that are generally similar to those in Fig. B2a, but of opposite intensity. Let us note that the polarization measurements from the space-borne POLDER sensor (Deschamps et al., 1994) were also used to estimate $R_{\mathrm{e}}$ of liquid water clouds across the globe (Bréon and Colzy, 2000) and seem to be in qualitative agreement with the findings of Fig. B2b.

During our assessment of 5 years of CALIOP data across the globe, we have observed significantly higher "unobstructed" OWC $S_{\mathrm{c}}$ values (i.e., $S_{\mathrm{c}}>20 \mathrm{sr}$, not shown in Fig. B2a) near the coasts of West Africa and over the region of SE Asia (e.g., see Young et al., 2018). These may be physically plausible and either (1) associated with small cloud $R_{\mathrm{e}}$, resulting from the Twomey's effect as explained above, or (2) associated with the presence of light-absorbing aerosols residing within the OWCs (Mishchenko et al., 2014; Chylek and Hallett, 1992; Wittbom et al., 2014). These aerosols would be undetected in our $\mathrm{IAB}_{\text {aboveCloud }}^{\mathrm{mol}}$ clear air selection method (see Appendix B2) and would impact the chemical composition of the cloud droplets, modifying their backscattered light. The latter is well illustrated in Fig. 8 of Deaconu et al. (2017), which shows simulations of cloud $S_{\mathrm{c}}$ with an imaginary part of the refraction index equal to 0.0001 , as a function of cloud droplet effective radius. Other reasons for these unusually high $S_{\mathrm{c}}$ values could be the sources of uncertainty noted (a), (b), (c) and (d) in the beginning of Appendix B, with (c) (i.e., the SNR of the backscatter data within the layer) possibly having a much higher impact on $S_{\mathrm{c}}$ than all other factors. An additional source of uncertainty on the retrieval of $S_{\mathrm{c}}$ could be a failure of the CALIPSO surface detection scheme. If CALIOP fails to detect the surface adequately, part of the Earth's surface could be misclassified as an opaque water cloud and these misclassified clouds would have abnormally high $S_{\mathrm{c}}$.

Let us note that the vast majority of the $S_{\mathrm{c}}$ values reported in the literature (i.e., in $\mathrm{Hu}$ et al., 2006; Liu et al., 2015; Deaconu et al., 2017) are estimated using a Mie code and not directly measured. However, none of these results show $S_{\mathrm{c}}$ values above $20 \mathrm{sr}$ for non-aerosol-contaminated OWCs. On the other hand (and to add a lower bracket on our OWC $S_{\mathrm{c}}$ calculations), none of these results show $S_{\mathrm{c}}$ values below 14 sr. For this reason, we have imposed an additional threshold on the OWC $S_{\mathrm{c}}$ values as part of step (S3) in Table B1: we delete any "unobstructed" OWC along the CALIOP track for which $S_{\mathrm{c}}>20 \mathrm{sr}$ (i.e., unrealistically small water cloud droplets) or $S_{\mathrm{c}}<14 \mathrm{sr}$ (i.e., unrealistically large water cloud droplets). Every OWC $S_{\mathrm{c}}$ value along the CALIOP track was then compiled to produce four global median seasonal $4^{\circ} \times 5^{\circ}$ maps of OWC $S_{\mathrm{c}}$ using 5 years of nighttime CALIOP data (from 2008 to 2012).

There is additional precedent for establishing an upper limit of $S_{\mathrm{c}}=20 \mathrm{sr}$. Note that, from Eq. (B6), the value of $\mathrm{IAB}_{\mathrm{SS}, \mathrm{CAC}}^{\mathrm{OWC}}$ corresponding to $S_{\mathrm{c}}=20 \mathrm{sr}$ is $0.025 \mathrm{sr}^{-1}$. As mentioned earlier, this is the same OWC IAB threshold value used by Chand et al. (2008) to identify their "clear air above" cases. 


\section{Appendix C: Acronyms}

\begin{tabular}{|c|c|}
\hline AAC & Aerosol above clouds \\
\hline AAOD & Absorption aerosol optical depth \\
\hline AOD & Aerosol optical depth \\
\hline$\tau_{\mathrm{AAC}}^{\mathrm{DR}}$ & Aerosol optical depth above clouds using the DR method \\
\hline AeroCom & Aerosol Comparisons between Observations and Models \\
\hline AERONET & AErosol RObotic NETwork \\
\hline AMSR-E & Advanced Microwave Scanning Radiometer - Earth Observing System \\
\hline ARCTAS & Arctic Research of the Composition of the Troposphere from Aircraft and Satellites \\
\hline ASR & integrated Attenuated Scattering Ratio \\
\hline BRDF & Bidirectional Reflectance Distribution Function \\
\hline $\mathrm{CAC}$ & Clear air above cloud \\
\hline CALIOP & Cloud-Aerosol Lidar with Orthogonal Polarization \\
\hline CALIPSO & Cloud-Aerosol Lidar and Infrared Pathfinder Satellite Observations \\
\hline CERES & Clouds and the Earth's Radiant Energy System \\
\hline $\mathrm{CF}$ & Cloud fraction \\
\hline CloudSat & NASA Earth observation satellite \\
\hline $\mathrm{COD}$ & Cloud optical depth \\
\hline $\mathrm{CR}$ & Color ratio technique \\
\hline DARE $_{\text {all-sky }}$ & Direct aerosol radiative effect in all-sky conditions (cloudy and non-cloudy) \\
\hline DARE $_{\text {cloudy }}$ & Direct aerosol radiative effect in cloudy conditions \\
\hline DARE $_{\text {non-cloudy }}$ & Direct aerosol radiative effect in non-cloudy conditions (clear-skies) \\
\hline DAREOWC & Direct aerosol radiative effect above opaque water clouds \\
\hline DISORT & DIScrete ORdinate Radiative Transfer solvers \\
\hline DR & Depolarization Ratio technique \\
\hline$\delta^{\mathrm{OWC}}$ & Layer-integrated volume depolarization ratio \\
\hline$f_{\mathrm{AAC}}$ & $\mathrm{AAC}$ frequency of occurrence \\
\hline HSRL & High spectral resolution lidar \\
\hline IAB & Integrated attenuated backscatter \\
\hline IBS & Integrated aerosol backscatter \\
\hline InWA & Indian ocean, offshore from western Australia \\
\hline LUT & Look-up table \\
\hline LWP & Liquid water path \\
\hline MBL & Marine boundary layer \\
\hline MCD43GF & MODIS BRDF/Albedo/NBAR CMG gap-filled products \\
\hline MODIS & MODerate Imaging Spectroradiometer \\
\hline$\eta^{\text {OWC }}$ & Layer effective multiple scattering factor \\
\hline NEAs & Northeast Asia \\
\hline $\mathrm{NEPa}$ & Northeast Pacific ocean \\
\hline NWPa & Northwest Pacific ocean \\
\hline OMI & Ozone Monitoring Instrument \\
\hline ORACLES & ObseRvations of Aerosols above CLouds and their intEractionS \\
\hline OWC & Opaque water cloud \\
\hline POLDER & Polarization and Directionality of Earth's Reflectances \\
\hline PBL & Planetary boundary layer \\
\hline$R_{\mathrm{e}}$ & Cloud droplet effective radius \\
\hline RT & Radiative transfer scheme \\
\hline$S_{\mathrm{a}}$ & Aerosol extinction-to-backscatter (lidar) ratio \\
\hline$S_{\mathrm{c}}$ & Cloud extinction-to-backscatter (lidar) ratio \\
\hline SCIAMACHY & Scanning Imaging Absorption Spectrometer for Atmospheric Cartography \\
\hline SEAs & Southeast Asia \\
\hline SEAt & Southeast Atlantic ocean \\
\hline SEPa & Southeast Pacific ocean \\
\hline
\end{tabular}


SEVIRI Spinning Enhanced Visible and InfraRed Imager

SNR Signal-to-noise ratio

SS Single scattering

SSA Single scattering albedo

SW Shortwave

TAt Tropical Atlantic ocean

TOA Top of atmosphere 
Author contributions. The overarching research goals were formulated by JR. MSK, SAY, and MAV influenced the evolution of these research goals. MSK carried out the formal analyses, investigations and visualizations and wrote the original draft. All coauthors have reviewed and edited the multiple drafts of the paper. The methodology behind the global application of the DR method to CALIOP measurements was first developed by YH, and adapted by MSK, SAY, MAV and KAP to accommodate the requirements of this study. The methodology for using this combination of ATrain satellites to infer aerosol intensive radiative properties was conceptualized by JR. The joint MODIS-OMI-CALIOP aerosol radiative properties were developed and provided by YS, JL and QZ. SL performed the radiative transfer calculations that provided direct aerosol radiative effects estimates in clear skies and above clouds.

Competing interests. The authors declare that they have no conflict of interest.

Acknowledgements. We thank the CALIPSO lidar science working group and data management team for their efforts in providing and discussing these datasets. We appreciate the comments of Abhay Devasthale and other reviewers that have helped us to improve the paper. We are grateful for comments from Paquita Zuidema and Robert Wood on cloud microphysics over the southeast Atlantic. We also thank Kristina Pistone for her help. This study was funded in part by NASA's Research Opportunities in Space and Earth Sciences (ROSES) program under grant NNH12ZDA001N-CCST.

Review statement. This paper was edited by Matthias Tesche and reviewed by Abhay Devasthale and two anonymous referees.

\section{References}

Alfaro-Contreras, R., Zhang, J., Reid, J. S., Campbell, J. R., and Holz, R. E.: Evaluating the impact of aerosol particles above cloud on cloud optical depth retrievals from MODIS, J. Geophys. Res.-Atmos., 119, 5410-5423, https://doi.org/10.1002/2013JD021270, 2014.

Alfaro-Contreras, R., Zhang, J., Campbell, J. R., and Reid, J. S.: Investigating the frequency and interannual variability in global above-cloud aerosol characteristics with CALIOP and OMI, Atmos. Chem. Phys., 16, 47-69, https://doi.org/10.5194/acp-16-472016, 2016.

Anderson, G., Clough, S., Kneizys, F., Chetwynd, J., and Shettle, E.: AFGL atmospheric constituent profiles $(0-120 \mathrm{~km})$, Tech. Rep. AFGL-TR-86-0110, Air Force Geophys. Lab., Hanscom Air Force Base, Bedford, Mass, 1986.

Anderson, T. E., Charlson, R. J., Winker, D. M., Ogren, J. A., and Holmen, K.: Mesoscale Variations of Tropospheric Aerosols, J. Atmos. Sci., 60, 119-136, 2003.

Arola, A., Eck, T. F., Huttunen, J., Lehtinen, K. E. J., Lindfors, A. V., Myhre, G., Smirnov, A., Tripathi, S. N., and Yu, H.: Influence of observed diurnal cycles of aerosol optical depth on aerosol direct radiative effect, Atmos. Chem. Phys., 13, 78957901, https://doi.org/10.5194/acp-13-7895-2013, 2013.
Bréon, F. M. and Colzy, S.: Global distribution of cloud droplet effective radius from POLDER polarization measurements, Geophys. Res. Lett., 27, 4065-4068, 2000.

Buras, R., Dowling, T., and Emde, C.: New secondary-scattering correction in DISORT with increased efficiency for forward scattering, J. Quant. Spectrosc. Ra., 112, 2028-2034, 2011.

Candlish, L. M., R. L. Raddatz, G. G. Gunn, M. G. Asplin and D. G. Barber: A Validation of CloudSat and CALIPSO's Temperature, Humidity, Cloud Detection, and Cloud Base Height over the Arctic Marine Cryosphere, Atmos. Ocean, 51, 249-264, https://doi.org/10.1080/07055900.2013.798582, 2013.

Chand, D., Anderson, T. L., Wood, R., Charlson, R. J., Hu, Y., Liu, Z., and Vaughan, M.: Quantifying above-cloud aerosol using spaceborne lidar for improved understanding of cloudysky direct climate forcing, J. Geophys. Res., 113, D13206, https://doi.org/10.1029/007JD009433, 2008.

Chand, D., Wood, R., Anderson, T. L., Satheesh, S. K., and Charlson, R. J.: Satellite-derived direct radiative effect of aerosols dependent on cloud cover, Nat. Geosci., 2, 181-184, https://doi.org/10.1038/ngeo437, 2009.

Chang, I. and Christopher, S. A.: Identifying Absorbing Aerosols Above Clouds From the Spinning Enhanced Visible and Infrared Imager Coupled With NASA A-Train Multiple Sensors, IEEE T. Geosci. Remote, 54, 3163-3173, 2016.

Chang, I. and Christopher, S. A.: The impact of seasonalities on direct radiative effects and radiative heating rates of absorbing aerosols above clouds, Q. J. Roy. Meteor. Soc., 143, 1395-1405, 2017.

Chin, M.: Atmospheric aerosol properties and climate impacts, Diane Publishing, 2009.

Chung, C. E., Ramanathan, V., Kim, D., and Podgorny, I. A.: Global anthropogenic aerosol direct forcing derived from satellite and ground-based observations, J. Geophys. Res., 110, D24207, https://doi.org/10.1029/2005JD006356, 2005.

Chylek, P. and Hallett, J.: Enhanced absorption of solar radiation by cloud droplets containing soot particles in their surface, Q. J. Roy. Meteor. Soc., 118, 167-172, 1992.

Costantino, L. and Bréon, F.-M.: Satellite-based estimate of aerosol direct radiative effect over the South-East Atlantic, Atmos. Chem. Phys. Discuss., 13, 23295-23324, https://doi.org/10.5194/acpd-13-23295-2013, 2013.

Cox, C. and Munk, W.: Measurement of the roughness of the sea surface from photographs of the sun's glitter, Josa, 44, 838-850, 1954.

Deaconu, L. T., Waquet, F., Josset, D., Ferlay, N., Peers, F., Thieuleux, F., Ducos, F., Pascal, N., Tanré, D., Pelon, J., and Goloub, P.: Consistency of aerosols above clouds characterization from A-Train active and passive measurements, Atmos. Meas. Tech., 10, 3499-3523, https://doi.org/10.5194/amt10-3499-2017, 2017.

De Graaf, M., Tilstra, L. G., Wang, P., and Stammes, P.: Retrieval of the aerosol direct radiative effect over clouds from spaceborne spectrometry, J. Geophys. Res., 117, D07207, https://doi.org/10.1029/2011JD017160, 2012.

De Graaf, M., Bellouin, N., Tilstra, L. G., Haywood, J., and Stammes, P.: Aerosol direct radiative effect of smoke over clouds over the southeast Atlantic Ocean from 2006 to 2009, Geophys. Res. Lett., 41, 7723-7730, https://doi.org/10.1002/2014GL061103, 2014. 
Deschamps, P. Y., Breon, F. M., Leroy, M., Podaire, A., Bricaud, A., Buriez, J. C., and Seze, G.: The POLDER mission: Instrument characteristics and scientific objectives, IEEE T. Geosci. Remote, 32, 598-615, 1994.

Devasthale, A. and Thomas, M. A.: A global survey of aerosol-liquid water cloud overlap based on four years of CALIPSO-CALIOP data, Atmos. Chem. Phys., 11, 1143-1154, https://doi.org/10.5194/acp-11-1143-2011, 2011.

Di Girolamo, L., Liang, L., and Platnick, S.: A global view of one-dimensional solar radiative transfer through oceanic water clouds, Geophys. Res. Lett., 37, L18809, https://doi.org/10.1029/2010GL044094, 2010.

Emde, C., Buras-Schnell, R., Kylling, A., Mayer, B., Gasteiger, J., Hamann, U., Kylling, J., Richter, B., Pause, C., Dowling, T., and Bugliaro, L.: The libRadtran software package for radiative transfer calculations (version 2.0.1), Geosci. Model Dev., 9, 1647-1672, https://doi.org/10.5194/gmd-9-1647-2016, 2016.

Feng, N. and Christopher, S. A.: Measurement-based estimates of direct radiative effects of absorbing aerosols above clouds, J. Geophys. Res.-Atmos., 120, 6908-6921, https://doi.org/10.1002/2015JD023252, 2015.

$\mathrm{Fu}, \mathrm{Q}$. and Liou, K.: On the correlated k-distribution method for radiative transfer in nonhomogeneous atmospheres, J. Atmos. Sci., 49, 2139-2156, 1992.

Guzman, R., Chepfer, H., Noel, V., Vaillant de Guélis, T., Kay, J. E., Raberanto, P., Cesana, G., Vaughan, M. A., and Winker, D. M.: Direct atmosphere opacity observations from CALIPSO provide new constraints on cloud-radiation interactions, J. Geophys. Res., 122, 1066-1085, https://doi.org/10.1002/2016JD025946, 2017.

Haywood, J. M. and Ramaswamy, V.: Global sensitivity studies of the direct radiative forcing due to anthropogenic sulfate and black carbon aerosols, J. Geophys. Res., 103, 6043-6058, https://doi.org/10.1029/97JD03426, 1998.

Holben, B. N., Eck, T. F., Slutsker, I., Tanré, D., Buis, J. P., Setzer, A., Vermote, E., Reagan, J. A., Kaufman, Y. J., Nakajima, T., Lavenu, F., Jankowiak, I., and Smirnov, A.: AERONET - A federated instrument network and data archive for aerosol characterization, Remote Sens. Environ., 66, 1-16, 1998.

Hu, Y., Vaughan, M., Winker, D., Liu, Z., Noel, V., Bissonnette, L., Roy, G., McGill, M., and Trepte, C.: A simple multiple scattering-depolarization relation of water clouds and its potential applications, Proceedings of 23nd International Laser Radar Conference, Nara, Japan, 24-28 July 2006, 19-22, 2006.

Hu, Y., Vaughan, M., Liu, Z., Lin, B., Yang, P., Flittner, D., Hunt, W., Kuehn, R., Huang, J., Wu, D., Rodier, S., Powell, K., Trepte, C., and Winker, D.: The depolarization-attenuated backscatter relation: CALIPSO lidar measurements vs. theory, Optics Express, 15, 5327-5332, https://doi.org/10.1364/OE.15.005327, 2007a.

Hu, Y., Vaughan, M., Liu, Z., Powell, K., and Rodier, S.: Retrieving Optical Depths and Lidar Ratios for Transparent Layers Above Opaque Water Clouds From CALIPSO Lidar Measurements, IEEE Geosci. Remote, 4, 523-526, $2007 \mathrm{~b}$.

Hu, Y., Winker, D., Vaughan, M., Lin, B., Omar, A., Trepte, C., Flittner, D., Yang, P., Nasiri, S. L., Baum, B., Holz, R., Sun, W., Liu, Z., Wang, Z., Young, S., Stamnes, K., Huang, J., and Kuehn, R.: CALIPSO/CALIOP cloud phase discrimination algorithm, J. Atmos. Ocean. Tech., 26, 2293-2309, 2009.
Hunt, W. H., Winker, D. M., Vaughan, M. A., Powell, K. A., Lucker, P. L., and Weimer, C.: CALIPSO lidar description and performance assessment, J. Atmos. Ocean. Tech., 26, 1214-1228, https://doi.org/10.1175/2009JTECHA1223.1, 2009.

Jethva, H., Torres, O., Remer, L. A., and Bhartia, P. K.: A color ratio method for simultaneous retrieval of aerosol and cloud optical hickness of above-cloud absorbing aerosols from passive sensors: Application to MODIS measurements, IEEE T. Geosci. Remote, 51, 3862-3870, https://doi.org/10.1109/TGRS.2012.2230008, 2013.

Jethva, H., Torres, O., Waquet, F., Chand, D., and Hu, Y.: How do A-train sensors intercompare in the retrieval of abovecloud aerosol optical depth? A case study-based assessment, Geophys. Res. Lett., 41, 186-192, https://doi.org/10.1002/2013GL058405, 2014.

Kacenelenbogen, M., Redemann, J., Vaughan, M. A., Omar, A. H., Russell, P. B., Burton, S., Rogers, R. R., Ferrare, R. A., and Hostetler, C. A.: An evaluation of CALIOP/CALIPSO's aerosol-above-cloud detection and retrieval capability over North America, J. Geophys. Res.-Atmos., 119, 230-244, https://doi.org/10.1002/2013JD020178, 2014.

Kassianov, E., Barnard, J., Pekour, M., Berg, L. K., Michalsky, J., Lantz, K., and Hodges, G.: Do diurnal aerosol changes affect daily average radiative forcing?, Geophys. Res. Lett., 40, 3265 3269, 2013.

Kim, S.-W., Chung, E.-S., Yoon, S.-C., Sohn, B.-J., and Sugimoto, N.: Intercomparisons of cloud-top and cloud-base heights from ground-based Lidar, CloudSat and CALIPSO measurements, Int. J. Remote Sens., 32, 1179-1197, https://doi.org/10.1080/01431160903527439, 2011.

Kim, M.-H., Omar, A. H., Vaughan, M. A., Winker, D. M., Trepte, C. R., Hu, Y., Liu, Z., and Kim, S.-W.: Quantifying the low bias of CALIPSO's column aerosol optical depth due to undetected aerosol layer, J. Geophys. Res.-Atmos., 122, 1098-1113, https://doi.org/10.1002/2016JD025797, 2017.

King, M. D., Platnick, S., Menzel, W. P., Ackerman, S. A., and Hubanks, P. A.: Spatial and temporal distribution of clouds observed by MODIS onboard the Terra and Aqua satellites, IEEE T. Geosci. Remote, 51, 3826-3852, 2013.

Klein, S. A. and Hartmann, D. L.: The seasonal cycle of low stratiform clouds, J. Climate, 6, 1587-1606, 1993.

Kovacs, T.: Comparing MODIS and AERONET aerosol optical depth at varying separation distances to assess ground-based validation strategies for spaceborne lidar, J. Geophys. Res., 111, D24203, https://doi.org/10.1029/2006JD007349, 2006.

Leahy, L. V., Wood, R., Charlson, R. J., Hostetler, C. A., Rogers, R. R., Vaughan, M. A., and Winker, D. M.: On the nature and extent of optically thin marine low clouds, J. Geophys. Res., 117, D22201, https://doi.org/10.1029/2012JD017929, 2012.

Levy, R. and Hsu, C.: MODIS Atmosphere L2 Aerosol Product. NASA MODIS Adaptive Processing System, Goddard Space Flight Center, USA, https://doi.org/10.5067/MODIS/MOD04_L2.006, 2015.

Liu, D., Wang, Z., Liu, Z., Winker, D. M., and Trepte, C.: A height resolved global view of dust aerosols from the first year CALIPSO lidar measurements, J. Geophys. Res., 113, D16214, https://doi.org/10.1029/2007JD009776, 2008.

Liu, Z., Kuehn, R., Vaughan, M., Winker, D., Omar, A., Powell, K., Trepte, C., Hu, Y., and Hostetler, C.: The CALIPSO cloud 
and aerosol discrimination: Version 3, Algorithm and test results, 25th International Laser and radar conference, 2010.

Liu, Z., Winker, D., Omar, A., Vaughan, M., Kar, J., Trepte, C., $\mathrm{Hu}$, Y., and Schuster, G.: Evaluation of CALIOP $532 \mathrm{~nm}$ aerosol optical depth over opaque water clouds, Atmos. Chem. Phys., 15, 1265-1288, https://doi.org/10.5194/acp-15-1265-2015, 2015.

Mace, G. G. and Protat, A.: Clouds over the Southern Ocean as Observed from The RV Investigator during CAPRICORN - Part 1: Cloud Occurrence and Phase Partitioning, J. Appl. Meteor. Climatol., 57, 1783-1803, https://doi.org/10.1175/JAMC-D-170194.1, 2018.

Matus, A. V., L’Ecuyer, T. S., Kay, J. E., Hannay, C., and Lamarque, J.: The role of clouds in modulating global aerosol direct radiative effects in spaceborne active observations and the Community Earth System Model, J. Climate, 28, 2986-3003, 2015.

McGill, M. J., Vaughan, M. A., Trepte, C. R., Hart, W. D., Hlavka, D. L., Winker, D. M., and Kuehn, R.: Airborne validation of spatial properties measured by the CALIPSO lidar, J. Geophys. Res., 112, D20201, https://doi.org/10.1029/2007JD008768, 2007.

Meyer, K., Platnick, S., Oreopoulos, L., and Lee, D.: Estimating the direct radiative effect of absorbing aerosols overlying marine boundary layer clouds in the southeast Atlantic using MODIS and CALIOP, J. Geophys. Res.-Atmos., 118, 48014815, https://doi.org/10.1002/jgrd.50449, 2013.

Meyer, K., Platnick, S., and Zhang, Z.: Simultaneously inferring above-cloud absorbing aerosol optical thickness and underlying liquid phase cloud optical and microphysical properties using MODIS, J. Geophys. Res.-Atmos., 120, 5524-5547, https://doi.org/10.1002/2015JD023128, 2015.

Min, M. and Zhang, Z.: On the influence of cloud fraction diurnal cycle and sub-grid cloud optical thickness variability on all-sky direct aerosol radiative forcing, J. Quant. Spectrosc. Ra., 142, 25-36, 2014.

Mishchenko, M. I., Liu, L., Cairns, B., and Mackowski, D. W.: Optics of water cloud droplets mixed with black-carbon aerosols, Opt. Lett., 39, 2607-2610, 2014.

Mitchell, R. M., Campbell, S. K., and Qin, Y.: Recent increase in aerosol loading over the Australian arid zone, Atmos. Chem. Phys., 10, 1689-1699, https://doi.org/10.5194/acp10-1689-2010, 2010.

O, K.-T., Wood, R., and Tseng, H.-H.: Deeper, precipitating PBLs associated with optically thin veil clouds in the $\mathrm{Sc}-\mathrm{Cu}$ transition, Geophys. Res. Lett., 45, 5177-5184, https://doi.org/10.1029/2018GL077084, 2018.

O’Connor, E. J., Illingworth, A. J., and Hogan, R. J.: A technique for autocalibration of cloud lidar, J. Atmos. Ocean. Tech., 21, 777-786, https://doi.org/10.1175/1520-0426, 2004.

Oikawa, E., Nakajima, T., Inoue, T., and Winker, D.: A study of the shortwave direct aerosol forcing using ESSP/CALIPSO observation and GCM simulation, J. Geophys. Res.-Atmos., 118, 3687-3708, https://doi.org/10.1002/jgrd.50227, 2013.

Omar, A., Winker, D. M., Vaughan, M. A., Hu, Y., Trepte, C. R., Ferrare, R. A., Lee, K., Hostetler, C. A., Kittaka, C., Rogers, R. R., Kuehn, R. E., and Liu, Z.: The CALIPSO automated aerosol classification and lidar ratio selection algorithm, J. Atmos. Ocean. Tech., 26, 1994-2014, https://doi.org/10.1175/2009JTECHA1231.1, 2009.
Oreopoulos, L., Cahalan, R. F., and Platnick, S.: The plane-parallel albedo bias of liquid clouds from MODIS observations, J. Climate 20, 5114-5125, 2007.

Peers, F., Waquet, F., Cornet, C., Dubuisson, P., Ducos, F., Goloub, P., Szczap, F., Tanré, D., and Thieuleux, F.: Absorption of aerosols above clouds from POLDER/PARASOL measurements and estimation of their direct radiative effect, Atmos. Chem. Phys., 15, 4179-4196, https://doi.org/10.5194/acp15-4179-2015, 2015.

Peng, Y., Lohmann, U., Leaitch, R., Banic, C., and Couture, M.: The cloud albedo-cloud droplet effective radius relationship for clean and polluted clouds from RACE and FIRE.ACE, J. Geophys. Res., 107, 4106, https://doi.org/10.1029/2000JD000281, 2002.

Penner, J. E.: Soot and smoke aerosol may not warm climate, J. Geophys. Res., 108, 4657 , https://doi.org/10.1029/2003JD003409, 2003.

Peters, K., Quaas, J., and Bellouin, N.: Effects of absorbing aerosols in cloudy skies: a satellite study over the Atlantic Ocean, Atmos. Chem. Phys., 11, 1393-1404, https://doi.org/10.5194/acp11-1393-2011, 2011.

Pinnick, R. G., Jennings, S. G., Chylek, P., Ham, C., and Grandy Jr., W. T.: Backscatter and extinction in water clouds, J. Geophys. Res., 88, 6787-6796, 1983.

Platnick, S., King, M. D., Meyer, K. G., Wind, G., Amarasinghe, N., Marchant, B., Arnold, G. T., Zhang, Z., Hubanks, P. A., Ridgway, B., and Riedi, J.: MODIS Atmosphere L3 Monthly Product, NASA MODIS Adaptive Processing System, Goddard Space Flight Center, USA, https://doi.org/10.5067/MODIS/MOD08_M3.006, 2015.

Platt, C. M. R.: Lidar and radiometric observations of cirrus clouds, J. Atmos. Sci., 30, 1191-1204, 1973.

Powell, K., Hunt, W., and Winker, D.: Simulations of CALIPSO Lidar Data, Proceedings of the 21st International Laser Radar Conference (ILRC), Quebec City, Quebec, 8-12 July 2002, available at: http://www-calipso.larc.nasa.gov/resources/pdfs/ILRC 2002/ILRC2002_Powell_Simulator.pdf (last access: 4 April 2019), 2002.

Powell, K. A.: Development of the CALIPSO Lidar Simulator, M.S. Thesis, Department of Applied Science, The College of William and Mary, 228 pp., 2005.

Powell, K. A., Liu, Z., and Hunt, W. H.: Simulation of Random Electron Multiplication in CALIPSO Lidar Photomultipliers, Proceedings of the 23rd International Laser Radar Conference (ILRC), Nara, Japan, 24-28 July 2006, available at: http://www-calipso.larc.nasa.gov/resources/pdfs/ILRC_ 2006/Powell-PhotomultiplierSimulation-2P-23.pdf (last access: 4 April 2019), 2006.

Powell, K. A., Hostetler, C. A., Vaughan, M. A., Lee, K. P., Trepte, C. R., Rogers, R. R., Winker, D. M., Liu, Z., Kuehn, R. E., Hunt, W. H., and Young, S. A.: CALIPSO lidar calibration algorithms - Part I: Nighttime 532-nm parallel channel and 532-nm perpendicular channel, J. Atmos. Ocean. Tech., 26, 2015-2033, 2009.

Powell, K., Vaughan, M., Winker, D., Lee, K.-P.. Pitts, M., Trepte, C., Detweiler, P., Hunt, W., Lambeth, J., Lucker, P., Murray, T., Hagolle, O., Lifermann, A., Faivre, M., Garnier, A., and Pelon, J.: Cloud-Aerosol LIDAR Infrared Pathfinder Satellite Observations (CALIPSO) Data Products Catalog, Document No: PC-SCI-503, Release 3.5, available at: https://www-calipso.larc. 
nasa.gov/products/CALIPSO_DPC_Rev3x5.pdf (last access: 12 October 2018), 2013.

Quijano, A. L., Sokolik, I. N., and Toon, O. B.: Radiative heating rates and direct radiative forcing by mineral dust in cloudy atmospheric conditions, J. Geophys. Res., 105, 12207-12219, https://doi.org/10.1029/2000JD900047, 2000.

Redemann, J., Vaughan, M. A., Zhang, Q., Shinozuka, Y., Russell, P. B., Livingston, J. M., Kacenelenbogen, M., and Remer, L. A.: The comparison of MODIS-Aqua (C5) and CALIOP (V2 \& V3) aerosol optical depth, Atmos. Chem. Phys., 12, 3025-3043, https://doi.org/10.5194/acp-12-3025-2012, 2012.

Redemann J., Shinozuka, Y., Kacenelenbogen, M., LeBlanc, S., Segal-Rozenhaimer, M., Vaughan, M., Stier, P., and Schutgens, N.: Use of A-Train aerosol observations to constrain direct aerosol radiative effects (DARE) and comparisons with AeroCom phase II DARE results, in preparation, 2019.

Remer, L. A., Kaufman, Y. J., Tanré, D., Mattoo, S., Chu, D. A., Martins, J. V., Li, R.-R., Ichoku, C., Levy, R. C., Kleidman, R. G., Eck, T. F., Vermote, E., and Holben, B. N.: The MODIS aerosol algorithm, products and validation, J. Atmos. Sci., 62, 947-973, 2005.

Rogers, R. R., Hostetler, C. A., Hair, J. W., Ferrare, R. A., Liu, Z., Obland, M. D., Harper, D. B., Cook, A. L., Powell, K. A., Vaughan, M. A., and Winker, D. M.: Assessment of the CALIPSO Lidar $532 \mathrm{~nm}$ attenuated backscatter calibration using the NASA LaRC airborne High Spectral Resolution Lidar, Atmos. Chem. Phys., 11, 1295-1311, https://doi.org/10.5194/acp11-1295-2011, 2011.

Rosen, J., Young, S., Laby, J., Kjome, N., and Gras, J.: Springtime aerosol layers in the free troposphere over Australia: Mildura Aerosol Tropospheric Experiment (MATE 98), J. Geophys. Res., 105, 17833-17842, https://doi.org/10.1029/2000JD900208, 2000.

Rosenfeld, D. and Lensky, I. M.: Satellite-based insights into precipitation formation processes in continental and maritime convective clouds, B. Am. Meteorol. Soc., 79, 2457-2476, 1998.

Russell P. B. R., Swissler, T. J., and McCormick, M. P.: Methodology for error analysis and simulation of lidar aerosol measurements, Appl. Optics., 18, 3783-3797, 1979.

Santese, M., De Tomasi, F., and Perrone, M. R.: AERONET versus MODIS aerosol parameters at different spatial resolutions over southeast Italy, J. Geophys. Res., 112, D10214, https://doi.org/10.1029/2006JD007742, 2007.

Sayer, A. M., Hsu, N. C., Bettenhausen, C., Lee, J., Redemann, J., Schmid, B., and Shinozuka, Y.: Extending "Deep Blue" aerosol retrieval coverage to cases of absorbing aerosols above clouds: Sensitivity analysis and first case studies, J. Geophys. Res.Atmos., 121, 4830-4854, 2016.

Schulz, M., Textor, C., Kinne, S., Balkanski, Y., Bauer, S., Berntsen, T., Berglen, T., Boucher, O., Dentener, F., Guibert, S., Isaksen, I. S. A., Iversen, T., Koch, D., Kirkevåg, A., Liu, X., Montanaro, V., Myhre, G., Penner, J. E., Pitari, G., Reddy, S., Seland, Ø., Stier, P., and Takemura, T.: Radiative forcing by aerosols as derived from the AeroCom present-day and pre-industrial simulations, Atmos. Chem. Phys., 6, 5225-5246, https://doi.org/10.5194/acp6-5225-2006, 2006.

Schutgens, N. A. J., Nakata, M., and Nakajima, T.: Validation and empirical correction of MODIS AOT and AE over ocean, Atmos.
Meas. Tech., 6, 2455-2475, https://doi.org/10.5194/amt-6-24552013, 2013.

Shinozuka, Y. and Redemann, J.: Horizontal variability of aerosol optical depth observed during the ARCTAS airborne experiment, Atmos. Chem. Phys., 11, 8489-8495, https://doi.org/10.5194/acp-11-8489-2011, 2011.

Stamnes, K., Tsay, S.-C., Wiscombe, W., and Jayaweera, K.: Numerically stable algorithm for discrete-ordinate-method radiative transfer in multiple scattering and emitting layered media, Appl. Opt., 27, 2502-2509, 1988.

Stein-Zweers D. and Veefkind, P.: OMI/Aura Multi-wavelength Aerosol Optical Depth and Single Scattering Albedo 1-orbit L2 Swath $13 \times 24 \mathrm{~km}$ V003, NASA Goddard Space Flight Center, Goddard Earth Sciences Data and Information Services Center (GES DISC), https://doi.org/10.5067/Aura/OMI/DATA2001, 2012.

Thorsen, T. J., Fu, Q., and Comstock, J. M.: Comparison of the CALIPSO satellite and ground-based observations of cirrus clouds at the ARM TWP sites, J. Geophys. Res., 116, D21203, https://doi.org/10.1029/2011JD015970, 2011

Thorsen, T. J. and Fu, Q.: CALIPSO-inferred aerosol direct radiative effects: bias estimates using ground-based $\mathrm{Ra}-$ man lidars, J. Geophys. Res.-Atmos., 120, 12209-12220, https://doi.org/10.1002/2015JD024095, 2015.

Thorsen, T. J., Ferrare, R. A., Hostetler, C. A., Vaughan, M. A., and $\mathrm{Fu}, \mathrm{Q} .:$ The impact of lidar detection sensitivity on assessing aerosol direct radiative effects, Geophys. Res. Lett., 44, 90599067, https://doi.org/10.1002/2017GL074521, 2017.

Torres O.: OMI/Aura Near UV Aerosol Optical Depth and Single Scattering Albedo 1-orbit L2 Swath $13 \times 24 \mathrm{~km}$ V003, Greenbelt, MD, USA, Goddard Earth Sciences Data and Information Services Center (GES DISC), https://doi.org/10.5067/Aura/OMI/DATA2004, 2006.

Torres, O., Hiren, J., and Bhartia, P. K.: Retrieval of aerosol optical depth above clouds from OMI observations: Sensitivity analysis and case studies, J. Atmos. Sci., 69, 1037-1053, 2012.

Toth, T. D., Campbell, J. R., Reid, J. S., Tackett, J. L., Vaughan, M. A., Zhang, J., and Marquis, J. W.: Minimum aerosol layer detection sensitivities and their subsequent impacts on aerosol optical thickness retrievals in CALIPSO level 2 data products, Atmos. Meas. Tech., 11, 499-514, https://doi.org/10.5194/amt11-499-2018, 2018.

Twomey, S.: Influence of pollution on shortwave albedo of clouds, J. Atmos. Sci., 34, 1149-1152, https://doi.org/10.1175/15200469(1977)034<1149:TIOPOT>2.0.CO;2, 1977.

Várnai, T. and Marshak, A.: MODIS observations of enhanced clear sky reflectance near clouds, Geophys. Res. Lett., 36, L06807, https://doi.org/10.1029/2008GL037089, 2009.

Vaughan, M., Powell, K., Kuehn, R., Young, S., Winker, D., Hostetler, C., Hunt, W., Liu, Z., McGill, M., and Getzewich, B.: Fully automated detection of cloud and aerosol layers in the CALIPSO lidar measurements, J. Atmos. Ocean. Tech., 26, 2034-2050, https://doi.org/10.1175/2009JTECHA1228.1, 2009.

Vaughan, M. A., Liu, Z., McGill, M. J., Hu, Y., and Obland, M. D.: On the spectral dependence of backscatter from cirrus clouds: Assessing CALIOP's $1064 \mathrm{~nm}$ calibration assumptions using cloud physics lidar measurements, J. Geophys. Res., 115, D14206, https://doi.org/10.1029/2009JD013086, 2010. 
Waquet F., Riedi, J., Labonnote, L. C., Goloub, P., Cairns, B., Deuzé, J.-L., and Tanré, D.: Aerosol Remote Sensing over Clouds Using A-Train Observations, J. Atmos. Sci., 66, 24682480, 2009.

Waquet, F., Peers, F., Ducos, F., Goloub, P., Platnick, S., Riedi, J., Tanré, D., and Thieuleux, F.: Global analysis of aerosol properties above clouds, Geophys. Res. Lett., 40, 5809-5814, https://doi.org/10.1002/2013GL057482, 2013a.

Waquet, F., Cornet, C., Deuzé, J.-L., Dubovik, O., Ducos, F., Goloub, P., Herman, M., Lapyonok, T., Labonnote, L. C., Riedi, J., Tanré, D., Thieuleux, F., and Vanbauce, C.: Retrieval of aerosol microphysical and optical properties above liquid clouds from POLDER/PARASOL polarization measurements, Atmos. Meas. Tech., 6, 991-1016, https://doi.org/10.5194/amt-6-9912013, 2013b.

Watson-Parris, D., Schutgens, N., Winker, D., Burton, S. P., Ferrare, R. A., and Stier, P.: On the limits of CALIOP for constraining modelled free-tropospheric aerosol, Geophys. Res. Lett., 45, 9260-9266, https://doi.org/10.1029/2018GL078195, 2018.

Wen, G., Marshak, A., Cahalan, R. F., Remer, L. A., and Kleidman, R. G.: 3-D aerosol-cloud radiative interaction observed in collocated MODIS and ASTERg images of cumulus cloud fields, J. Geophys. Res., 112, D13204, https://doi.org/10.1029/2006JD008267, 2007.

Wilcox, E. M.: Direct and semi-direct radiative forcing of smoke aerosols over clouds, Atmos. Chem. Phys., 12, 139-149, https://doi.org/10.5194/acp-12-139-2012, 2012.

Winker, D. M., Vaughan, M. A., Omar, A., Hu, Y., Powell, K. A., Liu, Z., Hunt, W. H., and Young, S. A.: Overview of the CALIPSO mission and CALIOP data processing algorithms, J. Atmos. Ocean. Tech., 26, 2310-2323, https://doi.org/10.1175/2009JTECHA1281.1, 2009.

Wittbom, C., Eriksson, A. C., Rissler, J., Carlsson, J. E., Roldin, P., Nordin, E. Z., Nilsson, P. T., Swietlicki, E., Pagels, J. H., and Svenningsson, B.: Cloud droplet activity changes of soot aerosol upon smog chamber ageing, Atmos. Chem. Phys., 14, 9831-9854, https://doi.org/10.5194/acp-14-9831-2014, 2014.

Xu, H., Guo, J., Ceamanos, X., Roujean, J.-L., Min, M., and Carrer, D.: On the influence of the diurnal variations of aerosol content to estimate direct aerosol radiative forcing using MODIS data, Atmos. Environ., 141, 186-196, 2016.

Yorks, J., Hlavka, D., Vaughan, M., McGill, M., Hart, W., Rodier, S., and Kuehn, R.: Airborne Validation of Cirrus Cloud Properties Derived from CALIPSO Lidar Measurements: Spatial Properties, J. Geophys. Res., 116, D19207, https://doi.org/10.1029/2011JD015942, 2011.

Young, S. A. and Vaughan, M. A.: The retrieval of profiles of particulate extinction from Cloud Aerosol Lidar Infrared Pathfinder Satellite Observations (CALIPSO) data: Algorithm description, J. Atmos. Ocean. Tech., 26, 1105-1119, https://doi.org/10.1175/2008JTECHA1221.1, 2009.

Young, S. A., Vaughan, M. A., Garnier, A., Tackett, J. L., Lambeth, J. D., and Powell, K. A.: Extinction and optical depth retrievals for CALIPSO's Version 4 data release, Atmos. Meas. Tech., 11, 5701-5727, https://doi.org/10.5194/amt-11-5701-2018, 2018.

Young, S. A., Vaughan, M. A., Garnier, A., Tackett, J. L., Lambeth, J. B., and Powell, K. A.: Extinction and Optical Depth Retrievals for CALIPSO's Version-4 Data Release, Supplementary Material, https://doi.org/10.5194/TBD, 2018.
Yu, H., Kaufman, Y. J., Chin, M., Feingold, G., Remer, L. A., Anderson, T. L., Balkanski, Y., Bellouin, N., Boucher, O., Christopher, S., DeCola, P., Kahn, R., Koch, D., Loeb, N., Reddy, M. S., Schulz, M., Takemura, T., and Zhou, M.: A review of measurement-based assessments of the aerosol direct radiative effect and forcing, Atmos. Chem. Phys., 6, 613-666, https://doi.org/10.5194/acp-6-613-2006, 2006.

Yu, H., Zhang, Y., Chin, M., Liu, Z., Omar, A., Remer, L. A., Yang, Y., Yuan, T., and Zhang, J.: An integrated analysis of aerosol above clouds from A-Train multi-sensor measurements, Remote Sens. Environ., 121, 125-131, 2012.

Yu, H. and Zhang, Z.: New directions: Emerging satellite observations of above-cloud aerosols and direct radiative forcing, Atmos. Environ., 72, 36-40, https://doi.org/10.1016/j.atmosenv.2013.02.017, 2013.

Zarzycki, C. M. and Bond, T. C.: How much can the vertical distribution of black carbon affect its global direct radiative forcing?, Geophys. Res. Lett., 37, L20807, https://doi.org/10.1029/2010GL044555, 2010.

Zelinka, M. D., Klein, S. A., and Hartmann, D. L.: Computing and Partitioning Cloud Feedbacks Using Cloud Property Histograms. Part I: Cloud Radiative Kernels, J. Climate, 833, 3715-3735, 2012.

Zhang, J., Reid, J. S., and Holben,B. N.: An analysis of potential cloud artifacts in MODIS over ocean aerosol optical thickness products, Geophys. Res. Lett., 32, L15803, https://doi.org/10.1029/2005GL023254, 2005.

Zhang, Z. and Platnick S.: An assessment of differences between cloud effective particle radius retrievals for marine water clouds from three MODIS spectral bands, J. Geophys. Res., 116, D20215, https://doi.org/10.1029/2011JD016216, 2011.

Zhang, Z., Ackerman, A. S., Feingold, G., Platnick, S., Pincus, R., and Xue, H.: Effects of cloud horizontal inhomogeneity and drizzle on remote sensing of cloud droplet effective radius: case studies based on large-eddy simulations, J. Geophys. Res., 117, D19208, https://doi.org/10.1029/2012JD017655, 2012.

Zhang, Z., Meyer, K., Platnick, S., Oreopoulos, L., Lee, D., and Yu, H.: A novel method for estimating shortwave direct radiative effect of above-cloud aerosols using CALIOP and MODIS data, Atmos. Meas. Tech., 7, 1777-1789, https://doi.org/10.5194/amt7-1777-2014, 2014.

Zhang, Z., Meyer, K., Yu, H., Platnick, S., Colarco, P., Liu, Z., and Oreopoulos, L.: Shortwave direct radiative effects of above-cloud aerosols over global oceans derived from 8 years of CALIOP and MODIS observations, Atmos. Chem. Phys., 16, 2877-2900, https://doi.org/10.5194/acp-16-2877-2016, 2016.

Zuidema, P., Redemann, J., Haywood, J., Wood, R., Piketh, S., Hipondoka, M., and Formenti, P.: Smoke and Clouds above the Southeast 25 Atlantic Upcoming Field Campaigns Probe Absorbing Aerosol's Impact on Climate, B. Am. Meteorol. Soc., 97, 1131-1135, https://doi.org/10.1175/BAMS-D-15-00082.1, 2016. 